surface present numerous little depressions resembling pin holes, which become much larger toward the root of the organ. These openings, which are also present in numbers on the region of the cheek, indicate the ducts of numerous mucous glands which lie immediately underneath the mucous membrane. The tongue of Beluga does not appear to differ much from that of other toothed whales. In Globiocephalus intermedius, according to MACALISTER, ${ }^{*}$ not only the tip, but also the margins of the organ are free, whereas in Beluga the latter are attached along nearly their whole length. Dr Murie $\dagger$ refers to the presence of a distinct frœnum in Globiocephalus melas, but this structure is not recognisable in Beluga. In respect of the very close attachment of the tongue to the sides and floor of the mouth, Beluga appears to approach the whalebone whales, in which the organ is perfectly immobile, and to differ in various degrees from the other toothed species, in nearly all of which greater mobility is conferred upon this organ than in the white whale. The presence of fringelike processes of mucous membrane on the margins of the tongue did not escape the notice of Professor Wyman $\ddagger$ in Beluga. They appear to be somewhat exceptional among the Cetacea. Dr JACKSon, $\S$ however, speaks of the tongue of the sperm whale as being provided anteriorly with "numerous fissures and granulations," an arrangement which appears to resemble closely that described above in Beluga. Their presence is also recorded by Dr MURIE $\|$ in Lagenorhynchus albirostris.

Salivary Glands.-The presence of these is doubtful. At the same time, it is well to state that we detected an apparently glandular body which occupied the usual position of the sub-maxillary gland. In size it resembled the gland of the same name in the human subject, and what we took to be a duct could be traced upward into the muscular substance of the tongue. The unsatisfactory condition of the parts, however, prevented its termination being clearly defined. Macalister I searched in vain for any trace of a salivary gland in Globiocephalus, but a rudimentary parotid was noticed by him in Baloenoptera rostrata.**

Tonsil and Uvula.-On opening the pharynx no trace of either of these structures could be distinguished. Such is also the case according to MurIE H and MACalister 杖 in Globiocephalus melas.

Pharynx.-The muscular wall of the pharnyx is separable into three distinct constrictors. The superior constrictor consists of two planes of fibres, readily separable one from another. These may be distinguished as the superficial and the deep. The superficial fibres arise in front of the blow hole, but, unfortunately, their exact attachment to the bone could not be made out,

* I. p. 230 .

|| V.p. 143.

$\ddagger \ddagger$ VI. p. 478.

VOL. XXIX. PART I. $\dagger$ II. p. 251.

Tा VI. p. 480 .

$\ddagger$ III. p. 610 .

I. p. 222 .
$\S$ IV. p. 140.

†† II. p. 253. 
as the pharnyx had been separated from the skull. These fibres pass backward on the side of the pharnyx, and become continuous with those of the opposite side behind that tube. They intermingle also with the fibres of the stylopharyngeus. The deeper fibres lie immediately under cover of the mucous membrane of the pharynx, and are most easily dissected from the inside of the tube. They form a constrictor or sphincter of the spiracle, and surround that cavity almost to its external opening. They are aggregated so as to form a muscular ring of great strength which surrounds the lower aperture of the spiracle. In other words, we have in these last mentioned fibres a means whereby the spiracular cavity may be shut off from the pharynx, whilst the upper fibres of the muscle may be regarded as being of service in producing alterations in the form and capacity of that chamber.

The Middle Constrictor arises from the posterior border of the thyro-hyal bone. The fibres pass backward, and blend behind the pharynx with those of the superior and inferior constrictors.

The Inferior Constrictor arises from the whole length of the superior border of the thyroid cartilage, including its posterior horn. It does not take any attachment to the cricoid cartilage. The fibres pass backward, and unite with those of the opposite side along the middle line posteriorly. A strong median raphé, to which the fibres of the constrictor muscles are attached, extends along the posterior aspect of the pharynx.

Stylo-pharyngeus Muscle arises from the base of the stylo-hyal bone. The fibres ascend obliquely upward and forward, and blend with those of the superior constrictor. It is a strong riband-like muscle, and when in action pulls the bag of the pharynx backward.

Palato-pharyngeus Muscle.-This muscle, which is described by both MuRIE* and Macalister + in Globiceps, could not be distinguished by us in Beluga.

The arrangement of the pharyngeal muscles above described closely resembles that observed by MacalisTer $f$ in Globiocephalus. The deeper layer of our superior constrictor evidently corresponds to the constrictor of the posterior nares of that author. According to him, in Globiocephalus the middle constrictor arises as in Beluga from the thyro-hyal bone, whilst Dr MURIE $§$ found it arising from the thyroid cartilage. In Beluga the origin of the inferior constrictor is confined to the thyroid cartilage, which is in accordance with Dr MurIE's observations on Globiocephalus. MACALISTER, $\ddagger$ on the other hand, observes that its fibres take an additional attachment to the cricoid cartilage in the latter species. Baloenoptera rostrata $\|$ differs from both in the rudimentary condition of the superior constrictor.

Esophagus. - This tube measures 10 inches in length. Its mucous membrane

* II. p. 254.

§II. p. 254. $\dagger$ VI. p. 480.

II I. p. 245. $\ddagger$ VI. p. 479. 
is thrown into well-marked longitudinal rugæ. It presented no trace of the glandular apertures described by Dr MurIE* in Globiocephalus melas, but it is possible that the somewhat unsatisfactory state of the part prevented the recognition of these in Beluga.

Stomach-External appearance.-When this viscus is distended with air and its exterior examined, the œsophagus appears to terminate at the junction of its first and second compartments, leading to the belief that it communicates with both. As we shall presently see, this appearance is deceptive, the œesophagus terminating in the first compartment, and in it alone. The latter, as in several other cetacea, resembles much the paunch of the ruminant. It measures 11 inches in length and 9 inches in greatest breadth. When viewed from below it appears to be of an oval form, an appearance which is due to the fact that when the parts are in their natural position the first is to some extent overlapped by the second compartment. When the latter is drawn aside the paunch is seen to be cordiform rather than oval, its rounded apex projecting horizontally backward. The second compartment measures 12 inches in length and $4 \frac{1}{2}$ inches in greatest breadth. It is oval in form, and tapers slightly to its posterior extremity which is closely applied to the wall of the cavity on its right. The third stomach is not visible externally, and consequently any description of the organ based upon the mere examination of its exterior is altogether misleading, so far as an accurate determination of the number of its cavities is concerned. The fourth stomach is reniform, and when distended measures 5 inches in length and $2 \frac{1}{2}$ in breadth. It is separated externally by a well-marked sulcus from the second compartment, which lies to its left. The fifth compartment, 13 inches in length, recalls to mind the form of the ruminant abomasum. Its left extremity is the larger, the diameter of its cavity diminishing slightly from its commencement to its termination. It extends for 9 inches to the right, and then curves upon itself to become continuous with the duodenum at the pylorus.

Interior of Stomach. - When the stomach is opened the osophagus is seen to terminate in the first compartment: the esophageal opening is of the same diameter as the rest of the tube. Immediately below, and slightly to the right of this aperture, is the orifice by means of which the first communicates with the second stomach. Its diameter is rather less than that of the œsophagus. A well-marked fold of mucous membrane extends from the inferior margin of the œsophageal opening, obliquely backward and to the right, and subsides on the superior wall of the second compartment after forming the superior lip of the aperture of communication between the first and second stomachs. This fold appears to correspond to the posterior lip of the cesophageal groove which in

* II. p. 256 . 
the ruminant extends from the œsophageal opening to the psalterium; it is so arranged as to form the inferior lip of the cardiac aperture and the superior lip of that between the first and second stomachs. The mucous lining of the first compartment is thick, and apparently devoid of glands. Its epithelial coat is corneous, and thrown into numerous anastomosing rugæ, which are irregularly disposed, and together present an arrangement not unlike that of the cerebral convolutions. This convoluted appearance of the mucous membrane is most distinctly marked toward the base of the stomach, and disappears altogether at its apex, the lining membrane in the latter situation being uniformly smooth and destitute of rugæ. The mucous membrane lining the channel of communication between the first and second stomachs is similar in character to that just described, but changes abruptly so soon as it enters the latter, where it assumes a soft and glandular character.

The second gastric compartment is provided with two apertures. Of these the first is situated on its left wall, an inch and a half from the œsophageal orifice, and opens up a communication between the first and second stomachs. It is of size sufficient to admit of the passage of two fingers. By means of the second opening, which is situated on the right wall of the cavity, three inches from its posterior extremity, the second communicates with the third compartment. This orifice is circular in form, and its diameter does not exceed half an inch. The mucous membrane of the second cavity is thick, soft, and glandular in character. It is thrown into several colossal rugæ, the largest of which measures one inch in height. They are more pronounced on the inferior and left than on the superior and right walls of the cavity, and are soft, glandular, and non-corneous, differing in these respects from the corresponding structures of the first compartment. They follow an irregularly serpentine course, giving off numerous secondary folds, the result being a generally convoluted arrangement of the mucous membrane not unlike that which we have described in the first stomach, but rather more open in character.

The third compartment is not recognisable externally. According to Dr Murie,* it is to be regarded simply as a canal of communication between the second and third (our fourth) stomachs. To us, for reasons to be presently stated, it appears to form a true subdivision of the stomach, and we shall describe it as such. It is situated between second and fourth compartments, and measures 3 inches in length and $2 \frac{1}{2}$ in greatest breadth. It is provided with two apertures, of which one, already described, is placed upon its left wall one inch behind its anterior cul-de-sac, and communicates with the second stomach; whilst the other, situated on the posterior extremity of the cavity, measures $\frac{1}{4}$ of an inch in diameter, and communicates with the compartment on its right. The mucous membrane is soft and smooth, resembling in these respects 
that of the fourth and fifth stomachs, and differing from that of the first and second.

The interior of the fourth stomach corresponds exactly in form to that of its exterior. On its left wall, two inches from its posterior extremity, is the opening above described, by means of which this compartment communicates with that on its left. The opening into the fifth stomach is circular in form, and measures about half an inch in diameter. It is placed in the anterior wall of the cavity. The mucous lining is soft, uniformly smooth, and destitute of rugae.

The cavity of the fifth stomach commences by a blind extremity or cul-desac, on the posterior wall of which, and two inches from its deepest part, is placed the opening by means of which the fourth communicates with the fifth stomach. The duodenal extremity of the latter is narrower than any other part, and is furnished with a well-marked ring-like pyloric valve, in the centre of which is a circular opening one-fourth of an inch in diameter. The diameter of this compartment diminishes gradually from its commencement to its termination, the latter being marked externally by a slight constriction. Its lining membrane resembles that of the fourth stomach, being smooth and devoid of ruga. None of the openings between the different gastric compartments presents the slightest trace of a valve. PERRIN * describes the canal-like communication between the second and third stomachs of Balcenoptera rostrato as being provided with a valve at each extremity.

From what has been said, it will be seen that in respect of the number of gastric cavities in Beluga, our observations agree with those of Professor WyMan, + and differ from those of Barclay.f The latter author describes and figures only four compartments in this species, and an examination of the drawing which he appends to his description shows conclusively that he failed to recognise the third compartment above described. This is less to be wondered at, seeing that the cavity referred to is not distinguishable externally from the second and fourth, between which it lies. Dr BARcLAY, however, describes correctly the character of the mucous membrane of such compartments as he examined.

An exact comparison of the stomach of Beluga with that of other cetaceans is, in the present state of our knowledge, well-nigh impossible, by reason of the diversity of statement which obtains with regard to the number of compartments in one and the same species according to different authors. In proof of this, we have thought it right to append the following tabular view of the observations of various anatomists who have examined the stomach of one or more species of cetacea:-

$$
\text { * VII. p. } 805 . \quad \quad+\text { III. p. } 607 . \quad \ddagger \text { VIII. p. } 382 .
$$


Toothed Whales.

\begin{tabular}{|c|c|c|c|c|c|c|c|c|}
\hline $\begin{array}{l}\text { Globio- } \\
\text { cephalus. }\end{array}$ & Grampus. & Delphinus. & Monodon. & Platanista. & Hyperoodon. & $\begin{array}{l}\text { Zyphiorryn- } \\
\text { chus. }\end{array}$ & Catodon. & Phocæna. \\
\hline \multirow{2}{*}{$\begin{array}{l}\text { Sp. Svineval. } \\
5 \text { Turner. } \\
5 \text { Jackson. } \\
4 \text { Murie. } \\
2 \text { Gulliver. }\end{array}$} & $\begin{array}{l}\text { Sp. grisens. } \\
5 \text { Fischer. }\end{array}$ & $\begin{array}{l}\text { Sp. tursio. } \\
4 \text { Hunter. }\end{array}$ & \multirow[t]{3}{*}{ 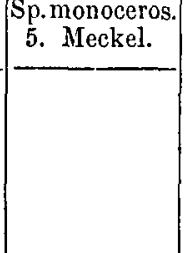 } & \multirow[t]{3}{*}{$\begin{array}{l}\text { Sp. gangetica. } \\
\mathbf{5} \text { Cuvier. }\end{array}$} & \multirow[t]{3}{*}{$\begin{array}{l}\text { Sp. bidens. } \\
7 \text { Hunter. }\end{array}$} & \multirow[t]{3}{*}{$\begin{array}{l}\text { Sp.cryptodon. } \\
8 \text { Burmeister. }\end{array}$} & \multirow[t]{3}{*}{$\begin{array}{l}\text { Sp. ? } \\
3 \text { Jackson. }\end{array}$} & \multirow{3}{*}{$\begin{array}{l}\text { Sp.comniunis } \\
4 \text { Turner. } \\
44 \text { Hunter. } \\
3 \text { Huxley. } \\
4 \text { Jackson. } \\
4 \text { Crisp. }\end{array}$} \\
\hline & $\begin{array}{l}\text { Sp. ? } \\
5 \text { Hunter. }\end{array}$ & \multirow[t]{2}{*}{$\begin{array}{l}\text { Sp. ? } \\
5 \text { Turner. } \\
5 \text { Jackson. }\end{array}$} & & & & & & \\
\hline $\begin{array}{l}\text { Pontoporia. } \\
4\end{array}$ & $\begin{array}{l}\text { Sp. Rissoanus. } \\
\mathbf{5} \text { Mrurie. }\end{array}$ & & & & & & & \\
\hline
\end{tabular}

Whalebone Whales.

\begin{tabular}{|c|c|c|}
\hline Balenoptern Sibbaldii. & Physalus antiquorum. & Balænoptera rostrata. \\
\hline at least 4 Turner. & 4 Murie. & $\begin{array}{l}5 \text { Carte and Macalister. } \\
5 \text { Hunter. } \\
4 \text { Perrin. }\end{array}$ \\
\hline
\end{tabular}

The diversity of statement brought out in the foregoing table regarding matters of fact is probably explicable on the supposition that different anatomists hold different views with regard to what ought to be considered a true gastric cavity, some regarding the duodenal dilatation so common among the cetacea as a true stomach, whilst others again look upon the third compartment described above as merely a communicating passage between the neighbouring cavities.

Among the upholders of the latter view, we may mention the name of $\mathrm{Dr}$ James Murie, who, in his elaborate monograph on Globiocephalus, adduces the following arguments in its favour. Dr MURIE* says:- "I look upon it (the cavity in question) only as a communicating canal, because of its diminutive capacity and diameter; because it is not at all a free chamber, but, strictly speaking, like the end of a bile duct, a tunnel burrowing its whole length betwixt the adjoining walls of II. and IV.; because of its smooth mucous membrane, showing few or no traces of digestion taking place therein; because the other four chambers agree with what obtains in Ploccena, Grampus, and Baloenoptera, and the two latter also offer an incipient structure of a similar kind, and corresponding in situation; and, lastly, because I regard certain of the so-called stomachs of certain Cetaceans (Hyperoodon, for example, with six or seven) as 
only canals between the true digestive chambers, as is shown above." Dr MURIE's opinion upon a subject of this kind is undoubtedly entitled to much weight, but we may be excused if we feel compelled to doubt the cogency of the arguments adduced in support of it. The diminutive size of what we regard as the third stomach in Beluga and Globiocephalus does not, it seems to us, militate against the view that the cavity ought to be regarded as a true stomach, inasmuch as we know that in many animals, e.g., birds, the true digestive juices are secreted by a glandular patch of extremely limited size as compared with the bulk of the stomach as a whole. That the cavity in question is not a free chamber, we are inclined to doubt, at least so far as Beluga is concerned; for, as the preceding description distinctly shows, the cavity is prolonged as a cul-de-sac in front of the most anterior of the two openings, by means of which it communicates with the neighbouring compartments. Add to which that in both Beluga and Globiocephalus the apertures of communication between the third compartment on the one hand, and the second and fourth on the other, are much narrower than the cavity itself, and it appears to us that the analogy between the latter and the passage of the bile duct through the walls of the intestine is satisfactorily disposed of. Professor TuRner* observes in his description of the stomach of Globiocephalus, that the uncous membrane of the third compartment "presented a few faintly-marked folds and gland orifices." The presence of the latter appears to us to be incompatible with Dr MuRIE's observation of the "smooth mucous membrane showing few or no traces of digestion taking place therein." The fact that both Grampus and Balcenoptera present traces of a similar structure, tends rather to support the view that Dr MurIE's so-called passage ought to be regarded as a true stomach, inasmuch as it is difficult to understand why, in the case of these different cetacea, an elongated passage occupying a definite position with reference to the other compartments should be substituted for the simpler arrangement, by means of which the first and second or the fourth and fifth compartments communicate with each other, if its function be merely that of a conduit, and not that of a true digestive cavity. Taking all the facts into consideration, therefore, we incline to the view that the third gastric cavity above described ought to be regarded as a true digestive organ rather than as a mere passage between the neighbouring compartments, - a view in which we are supported by the authority of both Dr JACKson $\dagger$ and Professor Turner, $\nmid$ founded upon an examination of the stomach of Globiocephalus.

Be this as it may, the table serves to show that in the majority of the toothed whales, in accordance with the observations of the greater number of anatomists, the stomach is divided into five distinct compartments. In this 
respect, therefore, Beluga agrees with these. The description of the form of the stomach in different species is not sufficiently exact to enable us to come to any conclusion with regard to the relation in which the latter stand to one another; but founding upon Dr Murie's* observation that the second and fourth compartments of the stomach of Risso's Grampus differ from those of Globiocephalus in respect of their more elongated and less globular form in the former, we may state that so far as this organ is concerned, Beluga appears to be more closely related to Grampus than to Globiocephalus.

In Grampus Rissoanus, however, Dr Murie observes that the opening, by means of which the second communicates with the third stomach, is situated close to that between the first and second compartments; whereas in Beluga, as we have seen, they are separated by an interval equal to two-thirds of the length of the second stomach. In this respect Beluga agrees with Globiocephalus rather than Grampus.

We have previously directed attention to the presence of a fold of mucous membrane, extending between the osophageal aperture of the first and the superior wall of the second compartment of the stomach in Beluga, and remarked upon the resemblance which it bears to the superior lip of the wesophageal groove of the ruminant stomach. A similar observation has been made by Dr Murie in his description of Globiocephalus. Whilst directing attention to the presence of this fold, however, we would wish to avoid attri. buting to it any physiological significance in tracing an analogy between the stomach of the ruminants and that of the cetaceans. Professor Turner,t founding on his observation that in Globiocephalus the oesophagus communicates freely with both the first and second stomachs, is of opinion "that a provision would seem to exist in this animal for permitting a process of rumination as far as regards the contents of these two compartments, and an additional link is established between the ruminant and cetacean stomach."

With this opinion we are unable to agree-Firstly, Because in the ruminants, in which alone do we know anything positive regarding the process of rumination, the food, after passing through the first, is regurgitated from the second stomach, and subsequent to undergoing a second process of mastication is passed into the third stomach, this transference of the bolus being effected by means of the œsophageal groove. In the cetacea, on the other hand, at least in Beluga and Globiocephalus, the osophageal groove is incomplete, and is therefore wholly inadequate to perform the function of a canal, by means of which the food could be transferred from one compartment of the stomach to another. It, noreover, differs from the corresponding structure in the ruminant stomach, inasmuch as it terminates in the second compartment of the viscus instead of 
the thir d. On the supposition, therefore, that a process of rumination takes place in the cetacea, we are compelled to assume that the food is regurgitated from either the first or second compartment, to be afterwards carried back into the same,-a process which, if it ever takes place, is essentially different to that which occurs in the true ruminants. Secondly, The strictly animal diet of the toothed whales may further be advanced as an argument against this view, the nature of the food precluding the necessity of a process which, so far as positive knowledge goes, is strictly confined to truly herbivorous mammalia. Thirdly, The form and arrangement of the teeth in the zoophagous cetacea is such as seems but ill-adapted for carrying out their part in the supposed function of rumination. As M. FISCHER* has well said, when discussing this hypothesis :- "Bon nombre de cétacés (Balein, Ziphius, Grampus) sont complétement dépourvus de dents ou n'en possèdent qua l'extrémité du rostre."

Intestine.-The gut from pylorus to anus measures 54 feet in length. At its commencement it is wider than elsewhere, its diameter here being double that of any other part of the intestine. This dilated portion measures 5 inches in length, and receives the previously united hepatic and pancreatic ducts which open into it 4 inches from the pylorus, after lying in the wall of the gut for a distance of 2 inches. Immediately beyond the duodenal dilatation the gut, when flattened, measures $2 \frac{1}{4}$ inches in breadth, whilst at its rectal extremity this measurement diminishes to $1 \frac{1}{4}$ inch. The intestinal tube, therefore, decreases from its commencement to its termination, but the calibre of its lower half is somewhat irregular in consequence of constrictions which occur every here and there. There is no trace of any subdivision of the gut into small and large intestines, and the cæcum is entirely absent. The intestine is attached to the superior abdominal wall by a mesentery measuring 9 inches in breadth.

The mucous membrane lining the duodenal dilatation is uniformly smooth and destitute of valvulæ conniventes. One inch beyond the point of entrance of the combined hepatic and pancreatic ducts, however, the valvulæ begin to appear. At first small and faintly marked, they rapidly become valvulæ and form circular valve-like projections, measuring $\frac{3}{4}$ of an inch in depth, attached to the entire circumference of the gut. These large folds alternate with others of smaller size, which do not extend round the entire gut. The larger valvulæe are found along the upper half of the intestine, but below this they become smaller, and are less regularly disposed. In the lower 9 feet of the gut they are scarcely recognisable. The mucous membrane beyond the duodenum possesses a delicate, soft, and velvety appearance. Beyond the pyloric valve the surface 
of the mucous membrane presents a cribriform aspect, due to the presence of a number of little apertures which are visible to the naked eye. These openings, which do not extend farther than 2 inches from the pylorus, appear to be the orifices of glands, in all probability corresponding to those of Brunner in other mammals, but the somewhat unsatisfactory state of the part prevented the recognition of such by means of the microscope. The Peyerian patches are eighteen in number. They are large, irregular in form, and the long diameter of each coincides with that of the intestine. They are mostly situated on the free side of the gut. The largest patches, measuring for the most part about 9 inches in length, are found near the duodenal extremity of the intestine. Those of the lower half of the gut do not exceed 2 or 3 inches in length. The largest patch of all, however, measuring 16 inches in length, and occupying the entire circumference of the intestine, terminates at a distance of $\mathbf{1 1}$ inches from the anus, beyond which point these glands are entirely wanting. The first Peyerian patch is situated 5 feet beyond the pyloric valve.

The intestinal arteries are very regular in their arrangement. They inosculate with one another so as to form a series of vascular arches, the summits of which abut against the wall of the intestine. From these arches numerous branches are given off for the supply of the gut, without the intervention of any secondary arcades. The veins are arranged in a similar manner.

The mesenteric lymphatic glands are aggregated so as to form a mass, measuring 13 inches in length and 3 inches in breadth, surrounding the main trunk of the mesenteric artery. The margins of this mass are irregular in consequence of the presence of outlying processes, which for the most part are prolonged toward the gut, and accompany the main branches of the mesenteric artery. In addition to this glandular mass, isolated lymphatic glands of large size are dispersed here and there between the mesenteric folds of peritoneum. The lymphatic vessels are very numerous, and run in bundles from the walls of the gut to the central glandular mass. They are richly provided with valves, which entirely prevent the passage of injection toward the gut, although it passes with the greatest ease in the opposite direction. The neighbouring lymphatic vessels communicate freely with one another.

According to Meckel,* in the cetacea the length of the intestine is to that of the body as 11 or 12 to 1 ; but an examination of the accompanying table will show that, except in the case of the porpoise, this estimate is too high :-

* XVIII. vol. vii. p. 388. 

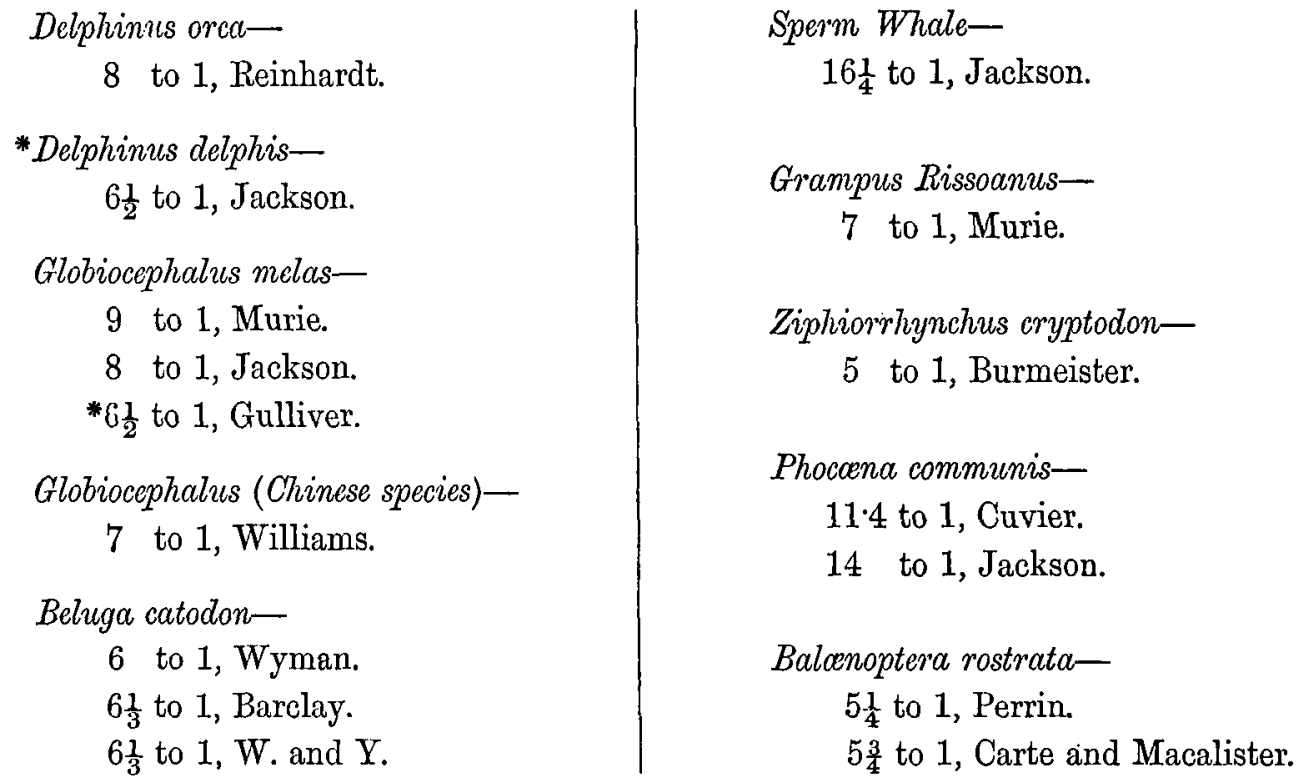

The table, moreover, shows that in the majority of the toothed whales the intestine relatively to the body is considerably longer than in the whalebone whales, only a single species of the former (Zyphiorrhynchus) possessing a relatively shorter alimentary canal than any member of the latter group.

So far as Beluga is concerned, it appears to occupy an intermediate position between the two.

In respect of the duodenal dilatation, Beluga agrees with nearly all the cetacea; and with the other tootled whales, in the absence of a cæcum or any distinction between the small and large intestines. Peyerian patches similar to those described in Beluga have been noticed in Globiocephalus melas, ${ }^{\dagger}$ Grampus Rissoanus, $\ddagger$ Baloenoptera rostrata, $\$$ Delphinus delphis,\| and Phoccena communis.\| In all probability more extended investigation will affirm their presence in all the species of cetacea. The mesenteric lymphatic glands of Beluga agree with those of Globiocephalus in the absence of any cavity in their interior resembling that described by ABERNETHy 9 in Balona.

Liver.-This viscus is of large size and extends from the cesophagus on the left to the curve of the fifth gastric compartment on the right. It measures 16 inches from right to left and 8 inches in greatest breadth from its attached to its free margin. The attached margin is thick and rounded, whilst the free border is thin and sharp. The anterior surface is closely attached to the diaphragm, whilst the posterior is in contact with the second and fifth gastric cavities. It presents no trace of subdivision into a right and left lobe. The organ is enclosed in a strong fibrous capsule, from the deeper aspect of which

* This specimen was foetal.

$\S$ I. p. 249 .
† II. p. 259.

॥IV. pp. 157 and 169. $\ddagger$ X. p. 133.

ศ XIII. p. 675. 
septal processes pass inward to the hepatic substance. There is no trace of a gall bladder. Neither did we observe any dilatation of the hepatic duct in the wall of the intestine similar to that described by Dr MURIE* in Globiocephalus. The hepatic duct measures 5 inches in length, and is united with the pancreatic duct an inch and a half before it reaches the wall of the intestine. The combined ducts enter the duodenum 4 inches beyond the pylorus.

In respect of the absence of any trace of subdivision of the liver into a right and left lobe, Beluga appears to differ from almost every cetacean in which that organ has hitherto been described. That this is not an exceptional arrangement, occurring in only a single specimen of the species, appears to be proved by the fact that neither BARCLAY and NEILL nor WYMAN make any mention of distinct hepatic lobes in the specimens which they examined; at the same time, it should be observed that variation in the relative sizes of the hepatic lobes in different individuals of the same species of cetacea does sometimes occur, as is evident from the observations of JACKson and Murie upon Globiocephalus, in which, according to the former, the right is two or three times larger than the left hepatic lobe, whilst the latter investigator found them to be of the same size. On the other hand, Beluga agrees with all the other cetacea (with the exception of Globiocephalus chinensis) + in the absence of a gall bladder, and with the majority of the toothed whales, $\downarrow$ in respect of the junction of the hepatic and pancreatic ducts previous to their passage through the intestinal wall. In Globiocephalus $\S$ and Grampus $\|$ Dr MurIE describes the hepatic duct as being dilated into a kind of reservoir, where it lies in the wall of the duodenum. No such arrangement was distinguishable in Beluga.

Pancreas. - This organ measures 10 inches in length and $2 \frac{1}{2}$ in greatest breadth. It is somewhat flattened from above downward, and its extremities are evenly rounded. It extends from the right side of the apex of the first gastric compartment to the pylorus, and is overlapped on its lower surface by the second cavity of the stomach. Its surface is distinctly lobulated. The duct, as already stated, unites with that of the liver an inch and a half before the latter passes through the intestinal wall.

The pancreas does not present much variety either in respect of form or relations in the cetacea. In Beluga it does not appear to differ in either of these particulars from what has been noticed in the other toothed whales.

Spleen.-This organ is small and cake-like. It is situated directly behind and in contact with the superior surface of the first gastric compartment, and touches the left extremity of the pancreas. It is irregularly rounded, and measures about 3 inches in diameter, with an average thickness of 1 inch.

* II. p. 261 † II. p. 261.

$\ddagger$ (In Zyphiorrhynchus these ducts open separately into the duodenum.)

§ II. p. $261 . \quad$ \|I X. p. 133. 
In respect of its uniformly smooth surface, the spleen in Beluga differs from that of many cetacea, a distinctly lobulated character of that organ being noted by several observers in other species. In several, accessory spleniculi are found, but of these there is no trace in Beluga. These spleniculi, however, appear to be variable within the limits of even the same species. Dr $\mathrm{J}_{\mathrm{ACKSON}}$ * describes them as being present in Globiocephalus, whilst Dr MURIE, ${ }^{\dagger}$ on the other hand, as distinctly affirms their absence. The position of the spleen, lying as it does in relation to the superior aspect of the first gastric compartment, appears to be constant in all forms of the cetacea.

\section{HYOID BONE.}

The hyoid bone is composed of the elements usually met with in the cetacea.

The basi-hyal measures $2 \frac{1}{4}$ inches in length and the same in breadth between the thyro-hyals. It is hexagonal in form. The posterior border affords attachment to the thyro-hyoid ligament, whilst the anterior articulates with the cerato-hyals. Of the two external borders of either side the anterior is occupied by the origin of the inter-hyoid muscle, whilst the posterior is continuous with the thyro-hyals. The lower surface is slightly convex, and presents a well-marked transverse ridge, to which a number of muscles, elsewhere described, are attached, whilst the upper surface is slightly concave.

Thyro-hyals.-Each measures $2 \frac{1}{2}$ inches in length and 1 inch in breadth at the base. Its free extremity is completed by a little cap of cartilage, and a plate of the same substance is interposed between the base of the thyro-hyal and the basi-hyal.

Cerato-hyals are entirely cartilaginous, and measure $1_{2}^{1}$ inch in length. Each is attached by one extremity through the medium of a capsular ligament to the free end of the stylo-hyal, whilst the other end lies in contact with a loose cartilaginous segment measuring half an inch in thickness, which separates it from the basi-hyal. The cerato-hyal is attached to the segment referred to by means of a fibrous capsule.

Stylo-hyals, measuring 4 inches in length and 1 inch in breadth, are somewhat flattened. Each is strongly curved towards the middle line, and is cartiliginous in its lower half.

\section{Muscles of Tongue and Hyoid Bone.}

By the time the subject came into our possession these muscles had to some extent been destroyed, partly by injury and partly by decomposition. We are, therefore, unable to give so satisfactory a description of them as we could desire. At the same time, we may be permitted to state that such observations as are here recorded are accurate so far as they go.

$$
\text { * IV. p. } 163 .
$$

VOL. XXIX. PART I.

\section{$\dagger$ II. See plate xxxiii. fig. 35.}

$$
\overline{\mathrm{j}} \mathrm{N}
$$


Sterno-hyoid Muscle.-Origin cut. The muscle is broad, flat, of great strength, and is inserted partly into a well-marked transverse ridge on the lower surface of the basi-hyal, but chiefly into the whole length of the thyro-hyal bone. It rests by its deeper surface on the sterno-thyroid and thyro-hyoid muscles.

In Globiocephalus * the muscle is similarly arranged, whilst in Baloenoptera rostrata $\dagger$ its insertion is limited to the basi-hyal bone.

Sterno-thyroid Muscle.-Origin cut. It is inserted into an oblique ridge on the outer surface of the thyroid cartilage, much as in the human subject.

In Globiocephalus $\ddagger$ the muscle agrees exactly with this description. In Balcenoptera rostrata $\$$ it is absent.

Thyro-hyoid Muscle is very strong. It arises from the oblique line above mentioned, of the thyroid cartilage. The fibres diverge as they pass forward, and are inserted into the whole length of the thyro-hyal as well as into the posterior border of the basi-hyal bone. The muscles of opposite sides are in contact at their origins, but diverge so as to leave an interval at their insertion.

In Globiocephalus, MACALISTER $\|$ observes that the muscle is inserted into the basi-hyal bone alone, whilst in Baloenoptera rostrata T its insertion is confined to the thyro-hyal.

Mylo-hyoid Muscle is broad and powerful. Its fibres arise from the whole length of the thyro-hyal bone, and pass forward toward the lower jaw, into which in all probability they are inserted. Unfortunately, the insertion had been cut before the specimen reached us. Its fibres are not transverse, as described by Dr MURIE ** in Globiocephalus, but longitudinal in direction.

Carte and Macalister $+t$ describe the muscles of opposite sides as blending along the middle line in Balcenoptera. Such is not the case in Beluga.

Genio-hyoid Muscle, broad and flat, consists of a single fleshy mass occupying the middle line of the lower jaw from the symphysis to the hyoid bone. It arises from the transverse ridge on the lower surface of the basi-hyal bone by means of a flattened tendon, and passes horizontally forward toward the lower jaw. Its insertion was cut, but a comparison of the parts with Dr MuRIE's drawing of those in Globiocephalus leaves little doubt that in Beluga the muscle is inserted exactly as in the Bottle-nose.

Genio-glossus Muscle.-The origin of this muscle was unfortunately divided, but the relative position and direction of its fibres appeared to indicate that it represented the genial fibres of the genio-hyo-glossus of other mammals, and that consequently it arose from the posterior aspect of the symphysis of the lower jaw. The fibres pass upward, and radiating as in the human subject are inserted into the under surface of the tongue from an inch behind the tip as far back as the cartilaginous cerato-hyals.

$+\mathrm{I} p 219$

$\|$ VI. p. $480 . \quad$ TI I. p. 219.

$\ddagger$ II. p. 263.

** II. p. 251 .

§ I. p. 219.

拉 II. plate xxxi. fig. 11 .

H I. p. 220 . 
None of the fibres of this muscle are inserted into the hyoid bone. In this respect Beluga differs from Globiocephalus, in which, according to Dr MUrLE, * they are inserted into the cerato-hyal and basi-hyal bones. A similar arrangement to that above described obtains, according to CARTE and MACALISTER, + in Balonoptera rostrata.

Stylo-glossus Muscle is narrow and riband-like, and arises from the junction of the upper and middle thirds of the stylo-hyal bone. It passes obliquely forward and downward, and is inserted into the lateral border of the tongue opposite the junction of the anterior and middle thirds of that organ. It rests upon the superficial surface of the next muscle.

In Globiocephalus this muscle appears to be much larger than in Beluga, and arises from the whole length of the stylo-hyal bone. The identification of this muscle with the stylo-glossus, described by CARTE and MaCALISTER $\Varangle$ in Baloenoptera, is somewhat difficult. These authors describe it as lying superficial to all the other lingnal muscles; whereas, in Beluga, it was concealed by the myln-hyoid. As, however, in Balcenoptera the last-named muscle appears to be narrower than in Beluga, it is not improbable that the difference in relative position of the stylo-glossus in the two species may be referable to this fact. Upon this hypothesis, the arrangement of the stylo-glossus is essentially the same in both.

Hyo-glossus Muscle arises from the transverse ridge on the lower surface of the basi-hyal bone under cover of the genio-hyoid muscle, as well as from the whole length of the stylo-hyal, and is inserted into the anterior two-thirds of the lateral margin of the tongue. It is placed between the stylo-glossus on the outer and the genio-glossus on its inner side.

The arrangement of this muscle seems almost identical with that described by STANnius $§$ in the porpoise, and differs from that of Globiocephalus, $\|$ in which the muscle consists of two distinct portions, one of which arises from the stylohyal bone. In Balcenoptera rostrata the origin of the hyo-glossus is confined to the thyro-hyal element.

Palato-glossus Muscle measures 5 inches in breadth. The fibres pass from the palate to the side of the tongue, where they intermix with the other muscles of that organ.

This arrangement is similar to that described by Dr MURIET in Globiocephalus.

$A$ muscle, which is difficult to identify with any of those described by $\mathrm{Dr}$ MURIE** in Globiocephalus, or by CARTE and MACALISTER tt in Baloenoptera, arises under cover of the hyo-glossus, from which, however, it is quite distinct and easily separable. It is narrow and riband-like, and arises from the free extremity of the thyro-hyal bone. It passes forward, crossing the outer side of
* II. p. 252.
† I. p. 231.
$\ddagger$ I. p. 231.
II II. p. 252.
TI II. p. 254.
* $\mathrm{II}$.
$\S \mathrm{XV} . \mathrm{p} .8$.
†† I. 
the stylo-hyal element, and is inserted into the margin of the palate corresponding to the junction of the latter with the tongue.

Inter-hyoideus Muscle arises from the whole length of the anterior border of the thyro-hyal, as well as from the outer border of the basi-hyal bone. Its fibres pass horizontally forward to be inserted into the stylo-hyal bone from end to end, as well as into the outer border of the cerato-hyal cartilage. This muscle fills up the interval between the various parts of the hyoid bone, and is concealed by the hyo-glossus.

The muscle does not differ much from that described by MuRIE * in Globiocephalus, by Stannius $\dagger$ in the porpoise, or by Carte and Macalister $\ddagger$ in Baloenoptera. The latter authors describe it as divisible into three portions, which they name the superficial hyo-ceratic, the deep hyo-ceratic, and the kerato-pharyngeus.

\section{LaRyngeal and RESPIRATORY Organs.}

Blow Hole.-The blow hole, situated on the top of the head $11 \frac{1}{4}$ inches behind the anterior extremity of the upper jaw, and 2 inches posterior to the level of the eye, is crescentic in form, with the concavity directed forward, and is considerably narrower than the chamber into which it leads. Its posterior lip overlaps the anterior. The thick cuticle of the exterior of the animal passes just within these lips, where it gives place to the mucous membrane of the nasal chamber. The latter is of a pure white colour, and on the anterior wall of the spiracle is raised so as to form two well-marked longitudinal bands, extending from the lower or laryngeal aperture obliquely upward and outward toward the external orifice of the spiracular cavity. From each of these bands others pass more or less horizontally outward, and subside on the lateral walls of the chamber. On the spaces between these bands are numerous small apertures indicating the ducts of mucous glands. Some of these, of large size, are formed by the junction of several smaller ducts, whilst others, and these form the majority, correspond to the ducts of isolated glandules. The apertures with their associated glands are found in abundance on the anterior and lateral walls of the spiracle, but much more sparingly on its posterior wall, where they are confined to its lower part. So far as the form and position of the blow hole is concerned, Beluga agrees closely with Grampus, Globiocephalus, and Lagenorhynchus.

Nasal Sucs.-Situated on the anterior wall of the spiracular cavity are the openings of the nasal sacs, which are two in number, one on either side of the middle line. The upper margin of that of the right side is $\frac{3}{4}$ th of an inch, and that of the left $1 \frac{1}{4}$ inches from the margin of the blow hole. Each has a depth

$$
\text { * II. p. } 264 . \quad \quad \dagger \text { XV. p. } 7 . \quad \text { I. p. } 235 .
$$


of $1 \frac{3}{4}$ inch, and measures 1 inch in diameter at its opening into the spiracle. They run obliquely forward and upward, their blind extremities lying between the integument and the wall of the skull, and contain a quantity of thick mucous-like material. Each is invested by a thick layer of muscular fibres, the exact arrangement of which could not be satisfactorily made out, owing to the separation of the soft parts from the cranium.

The number of the nasal sacs in Beluga appears to differ from that of the other whales in which these have been accurately described. According to Hunter, ${ }^{*}$ there are two pairs in the porpoise, whilst in Globiocephalus ${ }^{\prime}$ and Lagenorllynchus $\ddagger$ DrMuRIE describes three pairs, to which in Grampus Rissoanus a seventh must be added. The position of the nasal sacs in Beluga, projecting forward as they do from the anterior wall of the spiracle, and lying underneath the integument covering the maxillary bones, justifies us in regarding them as homologous with the premaxillary sacs described by Dr MuRIE in the species above mentioned. It is, however, to be observed, that in respect of the diminutive size of these sacs, Beluga differs much from the other forms referred to. As already stated, the exact arrangement of the muscles surrounding these sacs could not be satisfactorily determined; but this is the less to be regretted in view of the very elaborate description given of them by Dr MURIE in other cetacean forms.

\section{LARYNX.-The Cartilages.}

Thyroid.-The alæ of the thyroid cartilage join inferiorly at a somewhat obtuse angle, forming a broad cartilaginous plate, which measures 2 inches in its antero-posterior diameter. Each ala diminishes rapidly to a depth of $\frac{1}{2}$ an inch at its lateral aspect, and then as suddenly expands in a crescentic manner giving rise to the cornua of the thyroid cartilage. Of these the anterior (superior) measure $\frac{3}{4}$ th of an inch in length, and are curved downwards at their extremities, whilst the posterior (inferior), measuring $1 \frac{1}{2}$ inch in length, are curved downwards and forwards; the latter articulate by their extremities with the postero-external surface of the cricoid cartilage close to the posterior margin of the latter. The anterior margin of the thyroid cartilage affords attachment to the thyro-hyoid ligament.

The cricoid cartilage, as noted by BARCLAY and NeILL in their specimen, is deficient inferiorly, an interval of $\frac{1}{4}$ of an inch separating its lateral halves. Superiorly the cartilage measures 2 inches in depth, and presents a well-marked median ridge; the anterior border is vertical in its upper part, but beyond the facets for articulation with the arytenoid cartilages, it slopes rapidly backwards and downwards. The flat articular surface for the reception of the arytenoid

* XVI. p. 335.

† II. p. 245.

VOL. XXIX. PART I. $\ddagger$ V. p. 146.

-
$\S X$. p. 125.

50 
cartilage measures $1 \frac{1}{4}$ inch in length ; it is flat from above downwards and convex from within outwards. The posterior border of the cricoid is deeply notched in the middle line superiorly, the notch accommodating a corresponding projection of the first tracheal ring. Approaching the inferior extremities of the cartilage this border is interrupted by a deep crescentic fissure near the posterior extremity of which is the articular depression for the inferior cornua of the thyroid cartilage.

Arytenoid.-These cartilages, elongated and laterally compressed, measure $4 \frac{1}{2}$ inches in length. Each presents inferiorly an oblique basal surface and gradually tapers to a blunt and rounded apex, from which a spur-like process is prolonged obliquely downwards and outwards. The apices and processes of the two cartilages, when covered with mucous membrane, form the posterior thickened lip of the superior aperture of the larynx. The flattened inner surfaces of the arytenoid cartilages, though closely applied throughout their entire length, remain ununited except by fibrous membrane; there is no direct union such as MAYER* figures in Monodon monoceros.

The posterior border of each cartilage is straight as far down as the articular: surface, below which it curves outwards, downwards, and then inwards towards the interior of the larynx, where it recurves upon itself; situated upon this border, $3 \frac{1}{2}$ inches below the apex, is a well-defined tubercle marked on its internal aspect by an articular surface, by means of which the arytenoid articulates with the cricoid. From the tubercle a ridge extends upwards, the lower part of which affords attachment by means of a fibrous membrane to the basal portion of the epiglottic cartilage.

The cartilages of Santorini and of Wrisberg are entirely absent.

The cartilage of the epiglottis, elongated equally with the arytenoids, forms about half a cylinder, broadest below, and narrowing gradually towards the apex. By its base it is attached anteriorly to the upper border of the thyroid cartilage, whilst its postero-superior angles are connected to the ridges before referred to of the arytenoid cartilages. The apex of the epiglottic cartilage is prolonged outwards and backwards on each side of the middle line, and with its mucous covering forms the anterior lip of the superior laryngeal aperture.

\section{Ligaments of Larynx.}

The thyro-hyoid ligament, broad, flat; and thin, occupies the interspace between the hyoid bone and the thyroid cartilage; it is attached along the entire length of their adjacent borders. A crico-thyroid ligament extends between the anterior border of the cricoid to the posterior border and deep

* XIX. Taf. lxxxiv. 
surface of the thyroid cartilage. The posterior cornua of the thyroid are connected to the cricoid by means of strong capsular ligaments.

The form of the crico-arytenoid articulation is such as to admit of rotation of the arytenoid upon the cricoid cartilage, the effect of rotation inwards being to approximate the inferior borders of the arytenoid cartilages in the centre of the larynx, thus giving rise to the formation of two distinct channels, such as have been described by Dr Murie in Risso's Grampus.

The approximation of the inferior borders of the arytenoid cartilages is effected by the contraction of the thyro-arytenoid muscles.

\section{Muscles of the Larynx.}

Crico-arytcenoidei postici are very strong; they arise from the whole of the dorsal surface of the cricoid cartilage, and also from the tips of the posterior cornua of the thyroid; the fibres pass obliquely upwards and outwards, to be inserted into the outer extremities of the tuberosities of the arytenoid cartilages.

Thyro-arytenoide $i$ arise from the inferior mesial line of the thyroid cartilage, and are inserted into the inferior external angle of the arytenoid cartilage.

Arytenoideus.-This muscle arises between the superior surfaces of the arytenoid cartilages; it is limited to the basal third of these cartilages.

Hyo-epiglottic muscles Dr MURIE* describes as two in number. In Beluga the fibres are coalesced into a single muscular mass arising from the posterior borders of the cartilaginous cerato-hyals; the attachment to the stylo-hyals, noted by Mupí in Globiocephalus, does not exist in Beluga. The muscle is inserted into the posterior half of the lower surface of the epiglottic cartilage.

Crico-thyroid are strong muscles, which arise from the outer surface of the cricoid'cartilage. They separate as they pass forwards, and are inserted into the posterior border of the thyroid cartilage as well as into its posterior cornua.

With respect to the action of these muscles, the arytenoid and posterior crico-arytenoid muscles separate the lower borders of the arytenoid cartilages, increasing thereby the size of the rima-glottidis, whilst the thyro-arytenoids act in an opposite manner. The hyo-epiglottideus raises the epiglottis, and the crico-thyroids approximate the cartilages between which they are placed. The presence of the last-named muscles in an animal, which, so far as we are aware, is not gifted with voice, shows that they have other and probably no less important functions than that with which they are generally credited.

A comparison of the muscles of the larynx of Beluga with those of other whales, shows a close resemblance between them and those of Globiocephalus melas, ${ }^{\dagger}$ and a corresponding deviation in both from the arrangement met with in Balcenoptera rostrata. $\ddagger$ There are, however, two hyo-epiglottic muscles

$$
\text { * II. p. } 263 \text { (Giobiocephalus melas). } \quad \text { † II. p. } 263 . \quad \text { †. pp. 237, } 238 .
$$


both in Globiocephalus melas and in Baloenoptera rostrata, but inasmuch as in the last named these arise from the body of the hyoid bone, there is a difference of origin in the two species. In Beluga, on the other hand, as previously described, the two parts are fused into a single muscle. CARTE and MACALISTER * consider that three aryteno-epiglottidean muscles exist in Baloenoptera rostrata, whilst in Baloenoptera Sibbaldii, TuRner ${ }^{\dagger}$ found but one. Murieł affirms his inability to distinguish them in Globiocephalus melas; in Beluga they are certainly absent.

\section{Exterior of Larynx.}

The free larynx projects upwards from the floor of the pharynx, and measures $3 \frac{1}{2}$ inches in length. Flattened from side to side, and broad at its base, it is slightly constricted in the middle, and again expands, both as regards its antero-posterior and transverse diameters, at the apex. The epiglottis is rather higher than the arytenoid cartilages, in which respect Beluga differs both from Globiocephalus melas and Lagenorhynchus, in which the reverse is the case. The epiglottic section, broader than the arytenoid, is slightly curved transversely, so that the latter cartilages are to some extent embraced by the former. The posterior segment of the apical portion of the larynx, formed by the arytenoid cartilages, presents an emarginate notch similar to that described by MuRIE in Globiocephalus melas. The internal borders of these cartilages are in contact along the whole length of the tubular larynx. The upper opening of the latter is broad transversely, and furnished with an anterior and posterior thickened lip of mucous membrane, inclosing horn-like processes of the epiglottic and arytenoid cartilages respectively. A linear depression extends from base to apex of the lateral aspect of the organ; it indicates the borders of the epiglottidean and arytenoid cartilages, whilst another groove marks posteriorly the apposition of the arytenoid cartilages.

\section{Interior of Larynx.}

There is a complete absence of the true vocal cords; an appearance of such at first sight certainly exists, but upon more accurate examination this simulation of them is found to be due to the projection inwards of the sharp inferior borders of the arytenoid cartilages. It is, however, by no means improbable, as MECKEL $\$$ states, and with this view Dr MuRIE\| coincides, that these sharp edges may serve the purpose of vocal cords in the cetacea. The mucous membrane lining the posterior wall of the larynx is thrown into numerous longitudinal folds, whilst at the base of the epiglottis it is projected forwards, so as to form on each side of the middle line a pouch of size sufficient to admit

$$
\text { * I. pp. 237, } 238 . \quad \text { † XVII. p. } 237 . \quad \text { † II. p. } 264 . \quad \text { \ XVIII. p. 596. } \quad \| \text { X. p. } 129 .
$$


the point of the fore finger. This pouch is subdivided into a number of little saccules, which communicate freely with one another. It corresponds in position to the ventricles of the larynx in other mammalia, projecting outwards behind the cartilage of the epiglottis, and being invested externally by the fibres of the thyro-arytenoid muscles ; inferiorly it is concealed by the thyroid cartilage. The pouches of opposite sides are separated by a well-defined mesial fold of mucous membrane. The sacculated character of the mucous membrane just described is not confined to the larynx, but extends to the upper portion of the trachea.

Probably none of the soft parts in the greater number of species of cetacea have been more completely examined, or so fully described and figured, as those constituting the laryngeal apparatus. Comparing these descriptions* and figures with those here given of the corresponding parts in Beluga, it is evident that, in respect of general form, the laryngeal cartilages of Beluga resemble closely those of the toothed whales taken collectively, whilst among these they appear to approximate in character more particularly to those of Monodon monoceros. MAYER* figures, however, in the latter species, a direct union superiorly of the arytenoid cartilages, which is not found in Beluga.

In the toothed whales both the epiglottidean and arytenoid cartilages are prolonged to an almost equal extent (this condition being more especially noticeable in the females of different species); they are, moreover, united together by fibrous tissue throughout their whole length, and terminate superiorly in rounded and expanded apices, so that a free tubular larynx with a glottis bounded by thickened lips results.

To these sectional characteristics Beluga entirely conforms, and in this respect differs very strikingly from the group of whalebone whales. The latter are distinguished by very characteristic laryngeal features, which, nevertheless, are distinctly of the cetacean type. A free conical larynx exists, much shorter, however, than that of the toothed whales, and with correspondingly short epiglottidean and arytenoid cartilages, which do not possess expanded apices, and which, moreover, are not united together in the whole of their extent. Such union as does exist is limited to the basal portions of the cartilages, whilst their upper parts remain free, and hence " the respiratory canals appear undoubtedly to be less completely closed before than in the toothed whales." $\dagger$

ESCHRICHT and REINHARDT $\ddagger$ are of opinion " that the most essential peculiarity in the larynx of whalebone whales, as compared with that of the toothed whales, consists in its allowing the mucous membrane of the respiratory canals, by means of an opening on its ventral surface, to appear in the form of a sac with

\footnotetext{
* XIX. Taf. lxxxiv. fig. 104. † “Cetacea," p. 102, Ray Soc., $1866 . \quad \ddagger X X$. p. 101. VOL. XXIX. PART I. 
an exterior covering of a strong layer of muscles." That the presence of a ventral air-sac in connection with the larynx of whalebone whales is of constant occurrence may be correct; certainly in them it attains its greatest development. But it is by no means so clear that it can be regarded as a specific character of the whalebone group. On the contrary, the existence of a small but analogous sac which, as Dr MURIE * points out, "fills in great part the angle of junction between the enlarged epiglottis and the thyroid cartilage, but does not reach the posterior border of the latter," in Risso's Grampus, shows that the arrangement in question is not confined to the whalebone whales. In Beluga, as we have seen, the arrangement is similar to that described in Risso's Grampus, and Dr MurIE'st assertion that the above apparent distinction between the whalebone and toothed whales is one rather of degree than of kind, is thereby corroborated. The truth of this observation is rendered still more apparent by a comparison of Dr Murie's figure of the sac in Risso's Grampus with that of the same structure in the Balcenoptera Sibbaldii described by Professor Turner. $\ddagger$

Be this as it may, the great difference in the shape and connections of the liryngeal cartilages in whalebone whales, as contrasted with those of the toothed species, is sufficient to differentiate the two groups.

Cuvier $§$ affirms the absence both of ventricles and of vocal cords in the cetacean larynx, and, so far as the latter are concerned; we agree with his observations, notwithstanding Dr MurIE's $\|$ assertion that rudimentary vocal cords are present in the larynx of Grampus. At least in Beluga, with the exception of the free margins of the arytenoid cartilages, we could not distinguish any structure which could functionally represent these cords. With regard to the laryngeal ventricles, on the other hand, we must differ from the distinguished French anatomist. We have already directed attention to the presence in the larynx of Beluga of two pouches which correspond in position to the ventricles of other mammals, and that they ought really to be regarded as homologous with such seems proved by the following considerations :-Firstly, That their relation to the thyroid cartilage and to the thyro-arytenoid muscles is the same in both ; secondly, That in some ruminants, e.g., Saiga tartarica, 9 as pointed out by Dr Murie, the arrangement of the ventricles is similar to that described above in Beluga, these ventricles forming a single pouch which projects downward and backward into the hollow of the thyroid cartilage. In the ruminants referred to, moreover, as in those whales which possess a laryngeal sac, there is no trace of any other cavity which can correspond to the laryngeal ventricles. Thirdly, That this sac in Beluga is essentially a bilateral structure is shown by the presence of the anterior mesial fold in its interior, which, were it de-

\footnotetext{
* X. p. 127.

$\dagger$ X. p. 127.

$\S$ XXXI, vol. iv. p. 54.

II X. p. 130.

$\ddagger$ XVII. plate viii. fig. 36 .

I XXXIX. p. 491.
} 
veloped to a greater extent, would completely separate the two halves from each other, and cause them to communicate by distinct apertures with the interior of the larynx in precisely the same manner as the ventricles do in the majority of mammals.

We must either accept this view with regard to the homologies of the laryngeal sacs of the toothed whales, or regard them as structures altogether confined to the cetacea, and having no representatives in other mammals. The latter alternative we are by no means inclined to accept. Nor will it do to regard the sacs as homologous with the subepiglottic ventricle of the horse and ass, or with the large air space found in a corresponding position in certain of the quadrumana (Mandrill *), for the reason that the latter have no relation to the thyro-arytenoid muscles, which, in the animals referred to, maintain their normal relation to the ventricles of Morgagni, these ventricles occupying their usual position in the laryngeal cavity. A similar argument might be advanced with reference to the air sac which in Ateles projects outward between the thyroid and cricoid cartilages, and which, therefore, at first sight, presents an arrangement not unlike that of the large laryngeal sac of the whalebone whales. We are, therefore, by a process of exclusion, compelled to regard the laryngeal pouches of the toothed whales as homologous with the ventricles of Morgagni. Now, if we imagine these pouches (which communicate freely with one another by reason of the deficiency of the mesial septum) of the toothed whales to be inflated so that the single sac would project altogether beyond the space bounded by the laryngeal cartilages, by means of the interval between the cricoid and thyroid cartilages, we should have an arrangement essentially similar to that of the laryngeal sac in the whalebone whales. In connection with this difference in size and relations of the laryngeal sac in the whalebone, as contrasted with the toothed whales, it is interesting to observe the adaptive modification of the laryngeal cartilages in the latter. The cricoid cartilage in these is deficient inferiorly, and the neck or constricted portion of the enormous laryngeal sac is supported by the posterior cornua of the arytenoid cartilages; whereas in the toothed whales the cricoid is either complete or almost complete inferiorly, and the arytenoid cartilages are destitute of the peculiar posterior cornua which in the whalebone whales appear to supply the place of the deficient cricoid. Moreover, in the whalebone group the inferior angle of the thyroid cartilage is reduced to a mere tongue-like process, so that a large interval exists between its posterior extremity and the first complete tracheal ring, which interval permits of the passage outwards of the laryngeal pouch. In the toothed whales, on the contrary, the thyroid cartilage is not aborted in this manner, and the laryngeal pouch does not extend beyond the cavity of the

* XXXII. plate vii. figs. 1,2 , and 3. 
larynx. Lastly, the arrangement of the muscular fibres which lie in relation to the laryngeal pouch is essentially similar in the toothed and in the whalebone whales. Dr Murie,* in his article on Risso's Grampus, arrives at the conclusion that these fibres belong to the thyro-arytenoid muscles, and the description given above of these muscles in Beluga leaves no doubt of the accuracy of this opinion. The same author * observes that the thyro-arytenoid muscles in Grampus "evidently correspond to those transversely-striped whorled muscular fascicles which surround or form the exterior coat of the so-called air bag or laryngeal sac both in the Right, the Pike whale, and the Razor-back." A reference to Professor TuRner's $\dagger$ description of these fibres in Baloenopter'a Sibbaldii and to that of CARTE and MaCALISTER $\ddagger$ of the same in Baloenoptera rostrata, shows that in the whalebone whales the muscles of each side surrounding the laryngeal pouch are attached by one extremity to the angle of the thyroid, and by the other to the body of the arytenoid and free border of the cricoid cartilage. In other words, we have in them a muscle which corresponds exactly to the thyro-arytenoid of other mammals, including the toothed whales. The cricoid attachment of the muscle appears to militate against this interpretation, but as neither Turner nor Carte and MaCalister refer to a lateral crico-arytenoid, it seems by no means improbable that these cricoidal fibres may represent the crico-arytenoideus-lateralis.

Now, if we imagine the laryngeal sac above described in Beluga to be expanded so as to project beyond the larynx opposite the interval between the cricoid and thyroid cartilages, accompanied by an adaptive alteration in the form of these cartilages, we should have the pouch invested by an almost complete layer of circular muscular fibres similar to that described by SANDIfort, $\$$ Eschricht and Reinhardt, $\|$ Turner,, and Carte and Macalister $+\underset{+}{+}$ in different species of whalebone whales.

Taking then into consideration-1st, The essentially bilateral character of the laryngeal sac of the toothed whales; $2 d$, The relation in which it stands to the thyroid cartilage and to the thyro-arytenoid muscles,-we come to the conclusion that the relatively small pouches of the toothed whales are homologous with the ventricles of Morgagni of other mammals, and that the enormous laryngeal sac of the whalebone whales must be equally regarded as their morphological equivalent.

The comparative shortness and non-union apically of the epiglottidean and arytenoid cartilages has been already referred to as characteristic of the whalebone whales. A still more interesting modification of the arytenoid cartilages in that group appears to be consequent upon the condition of the
* X.p. 129.
$\S$ XXIV. p. 246.
$\dagger$ XVII. p. 238.
IIXX. p. 101.
† I. p. 238.
II XVII. p. 238. 
cricoid cartilage, which, less differentiated than usual from the succeeding tracheal rings to which it is united, is like them deficient ventrally. The interspace thus left is occupied by a membrane continuous with that which fills up the interval left by reason of a similar incompleteness of the anterior tracheal rings. The arytenoid cartilages are prolonged backwards and downwards to form posterior horns, which, reaching the lower part of the larynx, turn inwards and approach each other, leaving but a slight interval between their extremities. This interval in the recent state is occupied by a ligamentous band which connects the two posterior horns. Thus a distinct arch is formed, which, taking the place of the deficient ventral portion of the cricoid, apparently compensates for its loss.

So far as we can ascertain, the cricoid is never so incomplete ventrally in the toothed whales; on the contrary, it usually forms a distinct ring. In some species, however, e.g., Beluga, Phoccena communis, the ring is not quite perfect, although almost so. In no species of toothed whale yet described are the arytenoids prolonged into posterior cornua, as in the whalebone whales.

To summarise, in respect of the larynx Beluga conforms to the characteristics of the toothed whales in general; at the same time, possessing as it does a small laryngeal sac and a cricoid cartilage ventrally incomplete, it manifests a tendency toward the possession of that form of larynx met with in the group of whalebone whales.

Trachea.-The windpipe, from the posterior border of the cricoid cartilage to the point of bifurcation into its terminal bronchi, measures 6 inches in length. Somervhat flattened from above downwards, its greatest diameter is transverse, and measures 2 inches. Of the cartilaginous rings forming part of its wall there are fifteen, seven of which are situated in front of an accessory bronchus to be presently described. The rings, as a rule, are complete, and entirely surround the trachea; there is consequently an absence of the so-calied membranous portion of the trachea usually met with in other mammals. The three anterior rings, however, form an exception to the general rule, their ventral segments being deficient; the corresponding portion of the tracheal wall just behind the cricoid cartilage is therefore entirely membranous.

Bronchi.--The bronchi are three in number, of which two correspond to those commonly resulting from the bifurcation of the trachea; whilst the third (azygos) is given off from the trachea about $2 \frac{1}{4}$ inches in front of the bifurcation. This accessory bronchus passes to the right lung, and enters its inner surface 4 inches in front of the entrance of the principal or terminal bronchus. It is the smallest of the bronchi, measuring when flattened only $\frac{3}{4}$ of an inch in breadth. Of the principal bronchi, the right measures 4 inches in length from the tracheal bifurcation to the point at which the first intra-pulmonic air-tube is given off; whilst the left, between the corresponding points, measures but 
$2 \frac{1}{2}$ inches. Each is flattened from above downwards, and measures $1 \frac{1}{4}$ inch in breadth. They enter the mediastinal surfaces of the respective lungs about one-third nearer the apex than the base, and somewhat nearer the dorsal than the ventral margin of the latter. As in the trachea, so in the bronchi, the cartilaginous rings are complete. The mucous membrane lining the airpassages is thrown into longitudinal folds, as in the majority of the larger mammalia.

Lungs.-Each lung measures 18 inches in length from base to apex, and presents three uniformly smooth surfaces. Neither of the lungs shows the slightest trace of any tendency to lobar subdivision. The surfaces of the lung are parietal, mediastinal, and diaphragmatic-names which sufficiently indicate their relative positions and connections with surrounding parts. A thick and rounded superior border, as well as a thin and sharp inferior margin, are noticeable. Each principal bronchus enters the inner or mediastinal surface of the corresponding lung, as previously described; the single or accessory bronchus reaches the inner surface of the right lung, and enters its substance midway between the point of entrance of the principal bronchus and the apex. Upon the left side the principal bronchus, after entering the lung, furnishes a large offset, which runs forward towards the apex, whilst the main tube continues backward to the base of the organ, lying close to its mediastinal surface and superior border. From these primary tubes secondary branches pass off in all directions, except towards the inner surface of the lung. The subdivision of the bronchial tubes within the lung does not take place dichotomously, as in Balcenoptera Sibbaldii," but is quite irregular. The cartilaginous elements of the intra-pulmonic bronchi are in the form of complete rings, even where the latter do not exceed $\frac{1}{12}$ th of an inch in diameter. This recalls to mind the similar arrangement met with in the lungs of the Dugong.t Water injected into the main bronchus of the right lung does not distend the apex of this organ, which, indeed, can only be effected when the fluid is introduced through the medium of the accessory bronchus. From this circumstance, it appears that in Beluga the communication between the principal and accessory bronchi of the right lung is not so free as HunTER $\ddagger$ affirms it to be

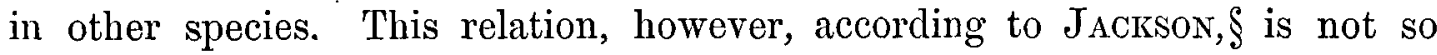
common as HunTER imagined.

The pleural membrane covering the lung is thick and leathery, but we could not distinguish any subjacent elastic coat such as is found in many of the larger mammals.

Lying in close relation to the inferior border of each lung, and near the junction of its diaphragmatic and inner surfaces, is a large lymphatic gland,

* XVIJ. p. 235. † XXI. vol. iii. p. 580. $\quad \ddagger$ XVI. p. $334 . \quad$ IV. 149. 
similar to that described by $\mathrm{Dr}$ MURIE ${ }^{*}$ as occupying a corresponding position in Globiocephalus melas. On the right side the gland measures 5 inches in length, and lies superficial to a second gland of equal size, which rests against the inner surface of the lung, and occupies the space between the ventral or inferior border and the hilum of the organ. On the left side there is but a single lymphatic gland, which corresponds in position to the most superficial of the two glands noted on the right side ; it is, however, not so large by onehalf. Numerous vessels radiate outwards from these glands as from a centre, and run upon the outer surfaces of the lung. Their exact nature could not be determined, but in all probability both sanguiferous and lymphatic vessels were present, as described by $\mathrm{Dr}$ Murie ${ }^{+}$in Globiocephalus melas. The lymphatic glands are invested superficially by pleural membrane prolonged from the surface of the lung. The glands of opposite sides are almost in contact, the interspace being occupied by pleural membrane, an arrangement which gives rise to the bridge-like appearance figured by Dr MurIE. $t$

Wyaran $\ddagger$ noted in his Beluga a free communication between the different parts of each lung. This, as we have pointed out, did not exist in our specimen. Barclay and NeILL $\S$ assert the osseous character of the intra-pulmonic bronchial rings. Probably, however, they were cartilaginous and not bony. With these exceptions--the pulmonary organs of Beluga, so far as they are described by the above-named observers, presented characters identical with those we have noted in the text. Both as regards their shape and unilobular character, the lungs of Beluga agree with those of almost every other cetacean.

Among the toothed whales, Globiocephalus melas $\|$ and Risso's Grampus if are described as possessing a more or less well-defined antero-inferior pulmonic lobe. BURMEISTER ** notes two unequal parts in the right lung of Epiodon cryptodon (GRAY); whilst Dr Williams tt asserts the existence in the Chinese Globiceps of two lobes in each lung. This lobulated condition has not, so far as we are aware, been described in any other toothed whale, nor in any member of the whalebone group. The large glandular bodies situated at the "post-ventral" margins of the lungs in Beluga appear to have been first fully described by

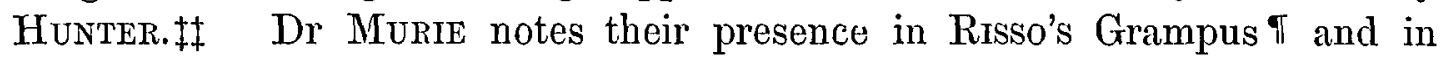
Globiocephalus melas; ${ }^{\dagger}$ they exist, moreover, in Delphinus tursio; 柑 also in Guldiver's, $§ \S$ Wildians', \|\| and JACKSON's Ti whales.****

In respect of their arrangement in the various species of Cetacea, the trachea and bronchi present but few variations from that described above in Beluga. So constant, indeed, is this arrangement of the respiratory channels in the different

* II. 265.

|| II. p. 265.

$\ddagger$ XXII. p. 107.
† II. p. 266.

I X. p. 131

$\S \S$ XXIII. p. 63. $\ddagger$ III. p. 610 .

** XLI. p. 96 .

IIII XIV. p. 412.
§ VIII. p. 388.

$\dagger \dagger$ XTV. p. 412.

गा IV. p. 164.

The specimens examing 
members of the group, that we find certain observers* affirming that the only exception is formed by the Greenland Right whale (Baloena mysticetus), in which, as SANDIFORT + first pointed out, the observation being subsequently corroborated by ESCHRICHT and REINHARDT, $\ddagger$ the trachea presents the peculiarity of "being only bifurcated into two bronchi, that branch, which in other cetaceans (and several land mammals) issues from the trachea before its bifurcation into those two bronchi, not being found here." There are, however, among the cetacea two other exceptions to what, in respect of the subdivisions of the trachea, may be called the usual arrangement. We refer to Pontoporia Blainvillii, in which Dr H. Burmeister $\S$ describes and figures a trachea which, previous to its bifurcation, givies off two accessory bronchi which pass, one to the right and the other to the left lung. A similar arangement has been described in Monodon monoceros. I Another interesting but less remarkable deviation from the usual arrangement was found by CARTE and MACALISTER $T$ in Balcenoptera rostrata. Here the three-fold bronchial arrangement exists, but the accessory bronchus, instead of coming from the trachea prior to its bifurcation, is given off further back than usual, and thus becomes an offset of the right principal bronchus. Balcenoptera thus presents an arrangement intermediate between that of the exceptional Greenland Right whale and that met with in the majority of the cetacea. Beluga, then, in respect of the respiratory organs, agrees with the greater number of cetaceans, and differs only in the relatively greater length of the trachea. Irregularity of the posterior tracheal rings, and incompleteness of those situated next the larynx, are met with in most cetaceans. The annular form of the intra-pulmonic bronchial cartilages is likewise common throughout the order.

\section{Circulatory Organs.}

Heart.-The heart is broad, and, as usual in cetaceans, is somewhat flattened from above downwards. Its length from base to apex corresponds to its basal breadth, the measurement in each case being 6 inches. The auricles are capacious, and possess large appendages. Internally, the walls of the auricles are for the most part quite smooth; each appendix, on the contrary, is provided with numerous well-developed trabeculæ carnex. These consist of fleshy bands, which, attached to the walls of the heart by their extremities, are free in the middle. They are not arranged in the regular, pectinate manner so common in the mammalian heart, but cross one another in all directions-those of the left side being more regularly disposed than are those of the right. The cavity of the right
* II. p. 265 ; XVII. p. 236.
$\S$ XXV.p. 484.
$\dagger$ XXIV. p. 245.
II XXVI. p. 139.
$\ddagger$ XX.p. 103.
fi I. p. 243 . 
auricle presents but two caval openings. Whether these were provided with valves or the reverse could not be ascertained, as the heart had unfortunately been damaged before coming into our possession. Instead of a single opening of the coronary sinus we distinguish two. They are placed close together in the usual position of that sinus, and are the orifices of two large veins, the trunks of which are situated in the right auriculo-ventricular and right ventricular grooves respectively. Neither of these openings presents the slightest trace of a Thebesian or coronary valve. It thus appears that in our specimen a coronary sinus, properly so called, does not exist ; but whether this is to be regarded as the normal arrangement of the cardiac veins in Beluga catodon, or merely as an individual peculiarity of exceptional character, can only be decided by more extended investigation. The cavity of the right ventricle presents no feature worthy of note, except the large size of the columnæe carneæ and musculi papillares. The right auriculo-ventricular valve consists of three cusps, which are arranged in the usual manner. It presents no trace of the remarkable perforation observed by MurIE* in Globiocephalus melas. In the left ventricle the papillary muscles and fleshy columns are of enormous size, the latter inter-crossing in all directions. The valves do not present any deviation from the arrangement usually found in the mammalian heart.

The Aorta arches over the root of the left lung. In addition to the coronary arteries for the supply of the heart, the arch of the aorta furnishes two innominate trunks, these being derived from its transverse portion. Each innominate artery measures 2 inches, and terminates by dividing into a common carotid for the supply of the head and neck, and a subclavian which is distributed to the flipper. The common carotid runs a short course of about half an inch, and then divides into two trunks of equal size, both of which run forward towards the head. Doubtless these represent the external and internal carotids. Their exact distribution could not be traced, owing to

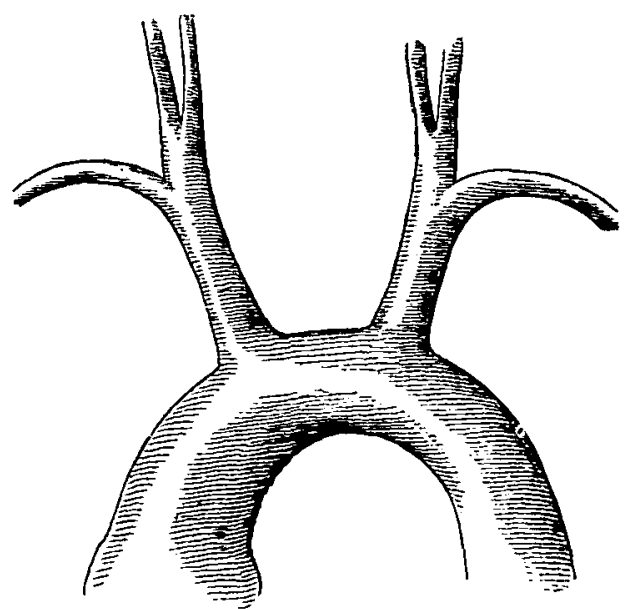

Beluga. - Semi-diagramatic view of the aortic arch and its branches, reduced.

the state of the parts. This was also the case with several large branches which, springing from the subclavian, passed to the parts about the scapula.

With reference to such points in the anatomy of the circulatory system as are noted in previously described Belugx, we find that the account given by WrMAN, ${ }^{\dagger}$ of the heart and aorta with its branches, agrees in the main with

* II. p. 266.

VOL. XXIX. PART I.
+ III. p. 608 .

$5 \mathrm{R}$ 
ours. This observer, however, notes a slightly notched condition of the cardiac apex which did not exist in our specimen. He makes no reference to the coronary sinus or to the openings of the cardiac veins, on which points Barclay and NeILL * are equally silent. The latter, indeed, do not appear to have examined the heart specially, and give no account whatever of the aorta and its branches.

Cetaceans in general agree with Beluga in possessing a heart characterised by its flattened character and capacious auricles. In no species is the substitution of two venous orifices in the place of a coronary sinus described; it may therefore in all probability be regarded as exceptional in Beluga. Dr J JCKSON $t$ affirms the existence of a single coronary opening, unprovided with any valve, in the spermaceti whale; Turner $\ddagger$ notes the presence of a coronary sinus, and the absence of any Thebesian valve, in the fœtus of Balcenoptera Sibbaldii; and BuRMEISTER $§$ speaks of the single orifice of the nutritive vein in Ziphiorrhynchus cryptodon (Epiodon sryptodon, Gray).

But, though no remarkable differences are to be found in the hearts of the different cetaceans, quite the reverse holds good with respect to the aorta and its branches, the differences in arrangement of these vessels being manifold. In most cetaceans the aorta is large at its commencement, but suddenly contracts in the arch-a condition first noticed by $J_{A C K S O N} \|$ in Phocana globiceps. The number of branches (exclusive of the coronary arteries) given off from the arch varies, as does also the arrangement of these. In Beluga two innominates, each dividing into a common carotid and a subclavian, are the only branches. Amongst the toothed whales two innominate trunks seem to be the rule; but in most cases an additional branch, such as a deep intercostal or superior thoracic branch, is also to be found springing from the arch. In Delphinus phoccena the left posterior thoracic occasionally springs from the arch; usually, however, the latter agrees with that of Beluga in simply giving off two innominates. According to Cuvier and MECKEL, in the porpoise each of these divides into a common carotid, subclavian, and vertebral, whilst Stannius, ${ }^{* *}$ RathKe, ${ }^{* *}$ Barkow, ${ }^{* *}$ and TuRner*** maintain that no common carotid exists, and that the external and internal carotid arteries arise separately from the innominate. In Globiocephalus Svineval, Turner I describes and figures two innominates and a left posterior thoracic as springing from the a.ortic arch, the external and internal carotids, together with the subclavian of each side arising directly from the trunk of the innominate artery. A similar arrangement is noted by Murie $t^{+}$in Risso's Grampus (Grampus Rissoanus).
* VIII. p. 380.
+ IV. p. 147 ,
$\ddagger$ XVII. p. 227.
\$ XII. p. 96 .
|| IV. p. 164.
ศा IX. p. 66.
** Quoted by Turner, IX. p. 66.
t† X. p. 133. 
The whalebone whales, in the matter of the aortic branches, resemble more closely of the arrangement met with in man. Carte and Macalister,** Turner,, Knox, $\ddagger$ Eschricht, $\S$ and Malm $\|$ all affirm the existence of a right innominate (which divides simply into a common carotid and a subclavian), as well as a left carotid and left subclavian, the three branches arising directly from the arch of the aorta.

Contrasting Beluga with the two sections, it is seen to agree with the toothed whales in so far as regards the existence of two innominate trunks, but to differ from them in the absence of additional branches from the arch, and in the more regular distribution of the innominates by means of a subclavian and a common carotid - the latter apparently not existing in other toothed whales, with the doubtful exception of Delphinus phoceena. From the whalebone whales it only differs in the fact that the common carotid and subclavian arteries on the left side do not come directly from the aorta, but from a left innominate trunk. Beluga, therefore, presents an arrangement which may be regarded as intermediate between the two sections.

\section{Brain and Organs of Sense.}

Brain.-This organ we did not examine, as the state of the parts precluded the possibility of obtaining an accurate and reliable description of its structure. Fortunately, we possess a means of supplementing this deficiency in our own observations, in an excellent paper with accompanying drawings, by Dr HerBERT MAJor, T published in the last number of the "Journal of Anatomy and Physiology." In it, in addition to the results of an elaborate investigation into its microscopic structure, with which we are not here immediately concerned, will be found the following description, by Professor Turner, of the cerebral convolutions in Beluga, drawn up from an examination of a photograph of the left hemisphere:-

"A well-marked Sylvian fissure was present on the outer surface of the hemisphere. The convolutions were arranged around this tissure in four successive tiers, separated from each other by three well-defined fissures which extended generally in the antero-posterior direction. On the inner surface of the hemisphere the convolutions presented considerable complexity, but they were obviously arranged in relation to the direction of the corpus callosum, and extended in the antero-posterior direction from the frontal end of the cerebrum backwards and downwards. There was evidence of a division of the convoluted mass into three successive tiers by intermediate furrows extending anteroposteriorly above the corpus callosum and the convolutions of the middle tier

* I. p. 245.
§ XXVIII. p. 104.
† XVII. p. 229.
\| XXIX. $\ddagger$ XXVII.

II XXX. p. 128. 
were in greater mass than those of either the upper or the lower tier. The convolutions of the two lower tiers reached the temporo-sphenoidal part of the hemisphere, while those of the upper tier did not extend so far down, but stopped at the occipital end of the cerebrum. The convolutionary arrangement, as above indicated, presented the closest similarity in both hemispheres."

Eye.-The eye is small, and is situated 9 inches behind the extremity of the muzzle.

Ear.-According to WYMAN, " the external auditory opening is "of a size sufficient to admit a bristle, and surrounded by a very slight elevation of the integument." According to BARCLAY, $\dagger$ no trace of an auditory opening is distinguishable.

\section{URINARY ORGANS.}

Kidney and Ureter.-The kidney has the form of an elongated flattened cake, measuring 9 inches in length, with an average breadth of $3 \frac{1}{4}$ inches. Its anterior extremity is rounded, whilst its posterior extremity is more pointed in form. The organ is enclosed in a stout fibrous capsule, upon opening whïch the kidney is seen to be composed of a number of distinct and easily separable lobules. Each of these has an average diameter of one-fourth of an inch, and is polygonal in form, so that the adjacent lobules, when in situ, are accurately applied to one another, only a delicate prolongation of the external capsule intervening, and forming a complete investment to each of them. The lobules are over 400 in number. Each in itself forms a complete renal organ, and is provided with a separate duct. The ducts, uniting with one another, finally give rise to the ureter. The renal blood-vessels enter the kidney close to its anterior extremity, whilst the ureter, formed as above described, and presenting no trace of a dilated portion or pelvis, passes off from the posterior extremity of the organ. The ureter is wide, and its walls are thin. It enters the bladder a short distance behind the neck, after traversing obliquely the coats of the viscus.

Bladder is small in size, and regularly pyriform. It measures 3 inches from base to apex. Its superior surface is entirely covered by peritoneum.

Urethra measures 3 inches in length, and is closely attached to the lower wall of the vagina. It opens into the vulva immediately behind the clitoris.

The urinary organs of Beluga differ but little from those of other cetacea. As observed by Gulliver, \$ Turner, $§$ and Murie\| in Globiocephrtlus, and by CARTE and Macalister $\Phi$ in Balcenopter $a$ rostrata, the renal vessels enter the kidney close to the anterior, whilst the ureter passes off from the posterior extremity of

* III. p. 610 .

$\S$ IX. p. 75 .
+ VIII. p. 394.

|| II. p. 284. $\ddagger$ XXIII. p. 65 .

T I. p. 251 . 
the organ. The same arrangement holds good in Beluga. In Lagenorliynchus * Dr MURIE noticed the coalescence of several of the renal lobules in contra-distinction to the isolated character of these in Globiceps and other species. But such was not the case in Beluga. As a rule, the urinary bladder seems to be of small size in the cetacea, the only exception being that of Zyphiorrynchus, in which, according to BuRMEISTER, + it is of large size. In respect of the size and form of this viscus, Beluga agrees with the majority of the cetacea.

\section{Female Generative Organs.}

Vulva.-The vulva is represented by an elliptical fissure 5 inches in length, the posterior extremity of which is situated three-fourths of an inch in front of the anus. The integument surrounding the former is smooth and elevated, so as to form two well-marked lateral pads representing the labia majora. Lying in the anterior commissure of the vulva, and to some extent concealed by the labia majora, are two well-defined folds of mucous membrane-the labia minora. Each measures 1 inch in length, and together they enclose an elliptical space in which lies the clitoris. The nymphæ are quite continuous with one another behind the clitoris, and form a prepuce for that body ; whilst in front of it they are lost in the anterior commissure of the vulva, where they become continuous with the inner surfaces of the labia majora. The body of the clitoris, measuring one-fourth of an inch in length, is conical in form, and somewhat flattened from side to side. 'The nymphæ unite with it and with each other along its posterior border.

The external genital organs do not appear to vary much in female cetaceans. Alike in the toothed and in the whalebone whales, there is a well.developed clitoris, together with labia majora and minora. With regard to the latter, Dr MurIe $\ddagger$ states that in Globiocephalus they form " two prominent folds of mucous membrane, each an inch in length, which lie within the anterior pudendal commissure, and slightly converge as they pass backwards." This arrangement appears to indicate an approach to that described above in Beluga, in which the labia minora unite with one another behind the clitoris to form the prepuce. In Balanopter a Sibbaldii, Professor TuRner $§$ observed that the labia minora " passed backward external to the meatus urinarius;" whereas in Beluga they become continuous with one another in front of that orifice.

Vagina.-The vagina measures 8 inches in length and $2 \frac{1}{2}$ in breadth when flattened. Its superior or dorsal surface is invested by peritoneum to within two inches of its posterior extremity, at which spot the serous membrane is reflected to the rectum. The inferior or ventral surface is also covered by peritoneum as far back as opposite the vesical extremities of the ureters, whence it is

* V. p. $149 . \quad$ † XLI. p. $97 . \quad \$$ II. p. $285 . \quad$ XVII. p. 201. VOL. XXIX. PAITT I. 
reflected to the superior wall of the bladder. The diameter of the vagina is uniform except at its uterine extremity, where it suddenly contracts to a breadth of an inch and a quarter, this contraction indicating externally the position of the os uteri in the interior. On slitting open the tube its mucous membrane is seen to be thick and of a milk-white colour, and to present different characters at different parts of the canal. Corresponding to its posterior fourth the lining membrane of the vagina is thrown into a number of longitudinally arranged colossal fleshy columns, which, in the second fourth of the canal are replaced by a series of very minute folds lying parallel to one another and to the long axis of the tube. In the anterior half of the vagina these rugæ are, as it were, doubled upon themselves at regular intervals, so giving rise to a series of circular valvelike folds, the free margins of which present a fringed or puckered appearance, and project into the lumen of the canal. Of these circular folds we counted eight. The most anterior of them is of larger size than the others, and closely surrounds the os uteri.

The condition of the vaginal mucous membrane above described appears to be constant in cetaceans. The number of transverse folds, however, varies in different species. Hunter describes two in the porpoise, and states that in some species there are as many as nine.* Dr Murie + counted four in Globiocephalus. Both Dr Murie $\ddagger$ and Professor Turner $§$ remark upon the similarity in appearance of these folds in Globiocephalus to the margins of the os uteri. The same observation holds good of Beluga.

Uterus and Fallopian Tubes.-The uterus lies between the widely expanded peritoneal folds, forming the broad ligament. The corpus uteri measures only 2 inches in length, its junction with the vagina being clearly indicated externally by the constriction before referred to. The os uteri, of very small size, is surrounded by the most anterior of the valve-like vaginal folds already referred to. Each of the anterior angles of the uterus is prolonged into the corresponding uterine cornu. The latter, 6 inches in length and $\frac{3}{4}$ of an inch in breadth, is flattened from above downward, and diminishing in size at the extremity to the thickness of a crow quill, becomes continuous with the Fallopian tube. This tube measures 3 inches in length, and continues of uniform diameter as far as its extremity, where it suddenly expands into a wide peritoneal infundibulum, altogether destitute of fimbriæ. Connected with each cornu uteri, and lying between the layers of the broad ligament, is a number of well-marked fibrous cords, which apparently represent the partially obliterated organ of Rosenmuiller. The mucous membrane of the corpus uteri, as well as of the cornua, is thrown into longitudinal folds, which diminish in size toward the abdominal opening of the Fallopian tube. A large number of blood-vessels

$$
\text { * XVI. p. 348. † II. see plate xxxviii. fig. } 74 . \quad \ddagger \text { II. } 285 . \quad \text { IX. p. } 76 .
$$


pass forward between the edges of the broad ligament, to be distributed to the uterine horns.

In certain cetaceans there appears to be no separation between the uterus and vagina, the difficulty of deciding where the one ends and the other begins being attributable to the absence of an os uteri. This condition has been noticed by $\mathrm{J}_{\text {ACKSON }} *$ in the sperm whale, and by Huxter ${ }^{\dagger}$ in Hyperoodon. The latter author says \$- "From the last projecting part" (i.e., the highest of the transverse vaginal folds above described) "the passage is continued up to the opening of the two horns, and the inner surface of this last part is thrown into longitudinal rugæ, which are continued into the horns. Whether this last part is to be reckoned common uterus or vagina, and that the last valvular part is to be considered as os tincæ, I do not know; but from its having the longitudinal rugæ, I am inclined to think it is uterus, this structure appearing to be intended for distinction." There is no doubt of the correctness of HunTER's conclusions when the uterus of either Globiocephalus or of Beluga, in both of which there is a clearly defined os uteri, is examined. At the same time that a transverse fold similar to those found in the vagina may occur in the body of the uterus itself, is proved by Dr MURIE's $\$$ observation on Globiocephalus, and justifies the difficulty which even JoHN HunTER experienced in fixing the limit between the two organs. The corpus uteri, when it can be clearly defined, is uniformly of small size in the cetacea.

The Fallopian tubes in Beluga resemble closely those of Hyperoodon. Hunter \| describes them in the latter as being remarkably small close to the uterus, but expanding gradually to their abdominal extremities, so that they resemble a French horn,-a description, the accuracy of which is shown by the accompanying drawing of the female organs in Beluga. Dr Murie I refers to the presence of fimbria at the extremity of the Fallopian tube in Globiocephalus. Beluga is destitute of such.

Ovary.-Of large size, and of an elongated oval form, the ovary measures $2 \frac{1}{2}$ inches in length and $\frac{3}{4}$ of an inch in breadth. It presents the appearance of being rolled upon itself round its transverse axis, the convex surface of the organ being directed upward and lying in contact with the superior layer of the ligamentum latum uteri. Its surface is thrown into five or six parallel longitudinal ridges which extend from end to end of the organ. A number of opaque fibrous cords radiate outward from the outer extremity of the ovary, lying between the layers of the broad ligament of the uterus. The exact nature of these is open to discussion. In addition to them, another series of obliterated tubules, before referred to, pass off from the anterior border of the organ, and

* IV. p. 145 .

$\S$ II. p. 285.
+ XXII. p. 112.

|| XVI. p. 349. $\ddagger$ XVI. p. 348.

TII. p. 285. 
are lost in the neighbourhood of the Fallopian tube. They are doubtless to be considered as representing the parovarium, or organ of Rosenmüller. No trace of Gaertner's canals could be made out. The surface of the ovary presented no appearance of either Graafian follicles or of ova.

The ovary of Beluga differs from that of Globiocephalus in its more elongated form, and in the presence of the superficial longitudinal ridges above referred to. This character, so far as we can ascertain, has not been noticed in any other cetacean with the exception of the sperm whale, in which, according to Dr JACKSON," the surface is "somewhat fissured." Dr MURIE $†$ describes the ovary in Globiocephalus as being arched over by a pavilion derived from the broad ligament of the uterus and the Fallopian tube. We could not distinguish this arrangement in Beluga.

Clitoris is formed by the junction of two crura, one of which is attached to each of the rudimentary pelvic bones. The latter are small, cylindrical in form, and measure $2 \frac{1}{2}$ inches in length and $\frac{1}{8}$ of an inch in transverse section. They are placed one on either side of the vagina at a depth of 3 inches from the surface, the anterior extremity of each in the natural position of the animal being directed obliquely downward and forward, whilst the posterior extremity looks upward and backward. The crus clitoridis, attached to the posterior half of the corresponding pelvic bone, is of large size, and covered by the fibres of a well-developed erector clitoridis. It unites with its fellow to form the body of the clitoris already described. In addition to the erector clitoridis, there were several other muscles attached to the pelvic bone which, so far as the state of the parts enabled us to observe, appeared closely to resemble those described by Dr Murie $\ddagger$ in Globiocephalus. We may therefore refer to the excellent monograph of that author, with its accompanying illustrations, for a more exact account of the muscles in this region than the somewhat unsatisfactory condition of the parts in Beluga permitted us to draw up.

Pelvic peritoneum almost completely envelopes the rectum to within 2 inches from the anal orifice, whence it is reflected to the vagina, the superior wall of which it invests to a corresponding extent. The inferior wall of the vagina is likewise covered by the serous membrane as far back as the base of the bladder. It may then be traced along the superior surface of that viscus from which it is reflected to the anterior abdominal wall, the whole of the lower surface of the bladder being thus devoid of peritoneal investment. The broad ligament of the uterus is arranged in the usual manner, and attaches the viscus to the lateral abdominal wall. Posterior to the ovary the peritoneum of the ligamentum latum is thick and leathery, but towards the free margin of the latter it is thin and transparent.
* IV. 146.
$\dagger$ II. p. 285.
$\ddagger$ II. p. 288. 
Mammu.*-The mammary gland, as usual in cetacea, lies alongside of the vulva; it measures 3 inches in length. The nipple is of small size, and is concealed in a slight depression of the integument $1 \frac{1}{4}$ inch from the margin of the genital fissure.

In respect of this gland Beluga does not differ from other cetacea. In Risso's Grampus Dr MuRIE † describes the erector clitoridis muscle as being functionally a compressor of the mammary gland; but in Beluga this muscle lies altogether on a deeper plane than the gland, and in close contact with the crus clitoridis, and cannot therefore act in the manner indicated.

\section{Male Generative Organs.}

These we have not ourselves had an opportunity of examining. With the view, however, of rendering the anatomical description of Beluga as complete as possible, we venture to transcribe the following observations by Dr BARCLAY $\ddagger$ upon the male genitals :--.

"The testicles we found within the abdomen, of an oblong shape, and lying close by the sides of the intestine, near its extremity. They were 4 inches in length, and the same in circumference. The penis was conical; at the apex $1 \frac{1}{2}$ inch in circumference, but 4 in circumference towards the base, near to which it exhibited a sigmoid flexure, owing to two very powerful muscles that seemed to have performed the office of retractors. Through its whole extent it was solt and flexible, without either a bone or a cartilage."

This description, incomplete as it is, seems to show that in respect of the male organs Beluga does not differ materially from Globiocephalus, Lagenor.hynchus, $\|$ and the other toothed whales.

\section{CONCLUDING REMARKS.}

In the present imperfect state of our knowlege of cetacean anatomy, it is impossible to arrive at any definite conclusion with regard to the relation in which Beluga stands to other genera. At the same time, a reference to the comparative observations contained in the foregoing pages serves to show that, so far as the soft parts are concerned, Beluga in many respects presents a close resemblance to Grampus and to Globiocephalus, whilst it differs from both in several minor particulars. From an examination of the skeleton, Professor

\footnotetext{
* According to FLOWER, the male mammary glands of cetacea were first discovered in Beluga by PALIJAS. $-P . Z$. S. S. i. 865.

$\dagger$ X. p. $122 . \quad$ † VIII. p. $384 . \quad$ IV. p. $164 . \quad$ || V. p. 149.

VOL. XXIX. PART I. 
FLower * concludes that " the Narwhal and the Beluga appear to separate themselves from all the rest by certain well-marked structural conditions, especially in the characters of the cervical vertebræ. As these two animals are in almost every part of their skeleton nearly identical," Professor FLower is disposed "to unite the two genera into a distinct subfamily, placing it next to the Platanistidæ." Unfortunately, such information as we possess regarding the soft parts of the Narwhal is of too imperfect a character to admit of the comparison being followed out. If, however, the number and arrangement of the nasal sacs, as forming an element in the determination of the affinities of different cetaceans, is deserving of the importance attributed to them by some writers, those of Beluga certainly seem to associate that genus with Monodon, and to separate it from the other genera above named. It should, however, be noted that the subdivision of the trachea into four bronchi in Monodon is widely different from that which obtains in Beluga and in every other toothed whale of which we have any knowledge, with the single exception of Pontoporia. In view of the scantiness of the information at our disposal regarding the anatomy of Monodon, we deem it inexpedient to pursue the comparison further at present, and shall leave the determination of the exact affinities of Beluga to be decided by future observers.

* Trans. Zool. Soc., vol. vi. p. 115. 


\section{EXPLANATION OF PLATES.}

\section{Piate VII.}

Figure 1. Internal female organs of generation, $\frac{1}{4}$ natural size. $v$. vagina; $u$. uterus ; c.u. c.u. cornua uteri ; f.t.f.t. Fallopian tubes; a.o.a.o. their abdominal openings; o. ovary; $r$ rectum.

Figure 2. Vagina and uterus laid open, $\frac{1}{2}$ natural size. o.u. os uteri ; v.f. folds of vaginal mucous membrane.

Figure 3. External female organs of generation, $\frac{1}{2}$ natural size. $c$. clitoris; l.m. labia minora; $n$. nipple; $v$. orifice of vagina; $\alpha$. anus.

Figure 4. Stomach laid open. The figures $1,2,3,4,5$ indicate the different cavities; ce. oesophagus; $d$. duodenum; $l$. liver; $h . d$. hepatic duct; $p . d$. pancreatic duct.

Figure 5. Exterior of stomach. The figures 1, 2, 3, 4, 5 indicate the gastric compartments; a. cesophagus; $d$. duodenum; l. liver; p.p. pancreas.

Figure 6. Spleen, about $\frac{1}{2}$ natural size.

Figure 7. Kidney, $\frac{1}{4}$ natural size.

\section{Plate VIII.}

Figure 1. Tongue and larynx. $L$. larynx ; $T$. tongue.

Figure 2. Deep muscles of tongue and hyoid bone. G.g. genio-glossus; St.g. stylo-glossus; Hy.g. hyo-glossus; My.hy. mylo-hyoideus; Th.hy. thyro-hyoideus; C.th. crico-thyroideus; St.th. sterno-thyroideus; I.h. interhyoideus; *. muscle described on page 411 of the text.

Figure 3. Superficial muscles of tongue and hyoid bone. G.hy. genio-hyoideus; My.hy. mylohyoideus; St.hy. sterno-hyoideus.

Figure 4. Hyoid bone and laryngeal cartilages seen from below, about $\frac{1}{4}$ natural size. $B . h$. basi-hyal; T.h. thyro-hyal; C.h. cerato-hyal; St.h. stylo-hyal; $T$. thyroid cartilage; C.C. cricoid cartilage.

Figure 5. Blow-hole and nasal sacs seen from within, $\frac{1}{2}$ natural size. B. blow-hole; N.S. N.S. nasal sacs.

Figure 6. Laryngeal cartilages, lateral view. $A$. arytenoid cartilage; $E$. cartilage of epiglottis; $T$. thyroid cartilage seen in section; $C$. cricoid cartilage.

Figure 7. Trachea and lungs. T. trachea; L.L. lungs; L.G. pulmonic lymphatic glands. 
Vol XXIX Plate VII

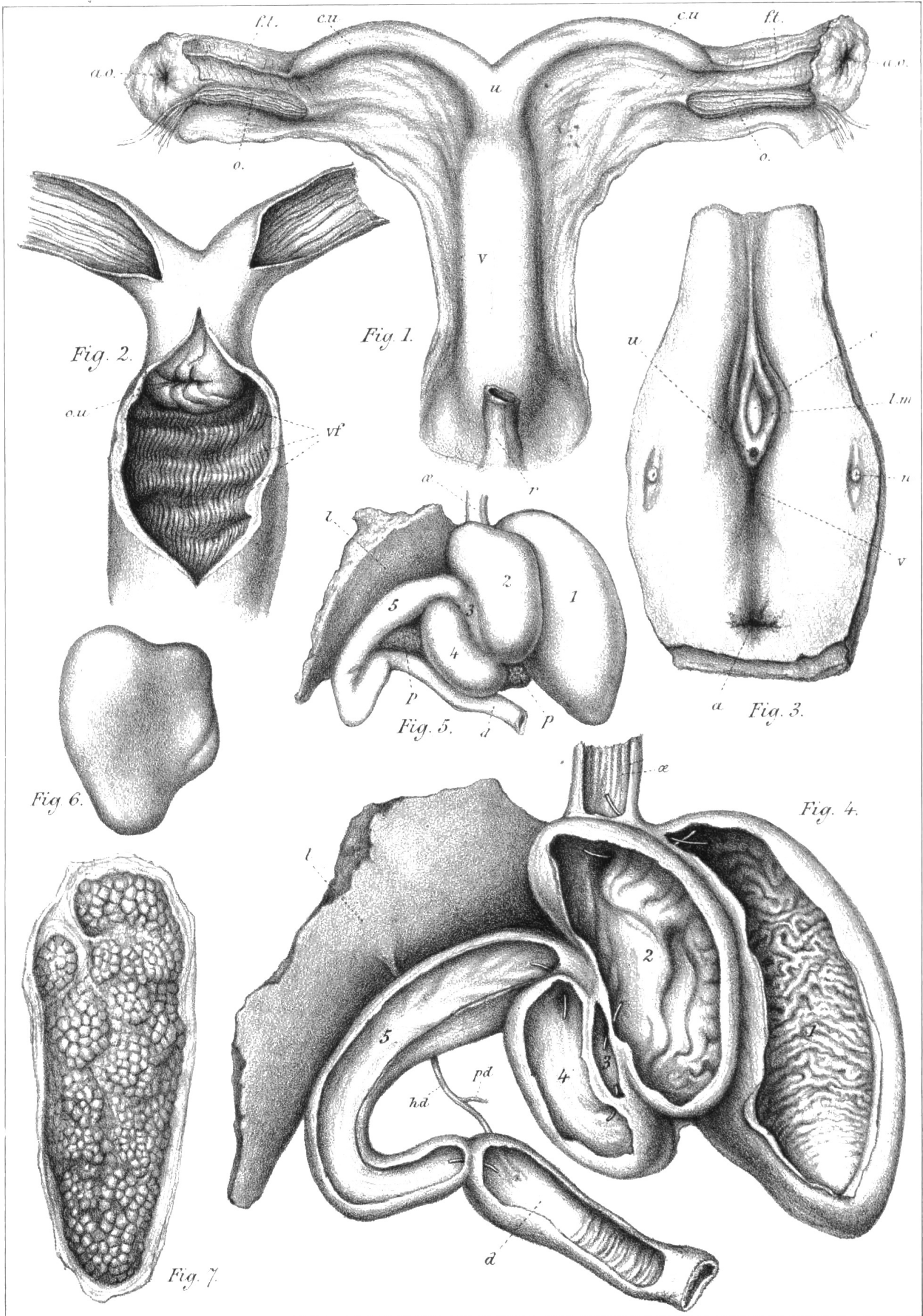




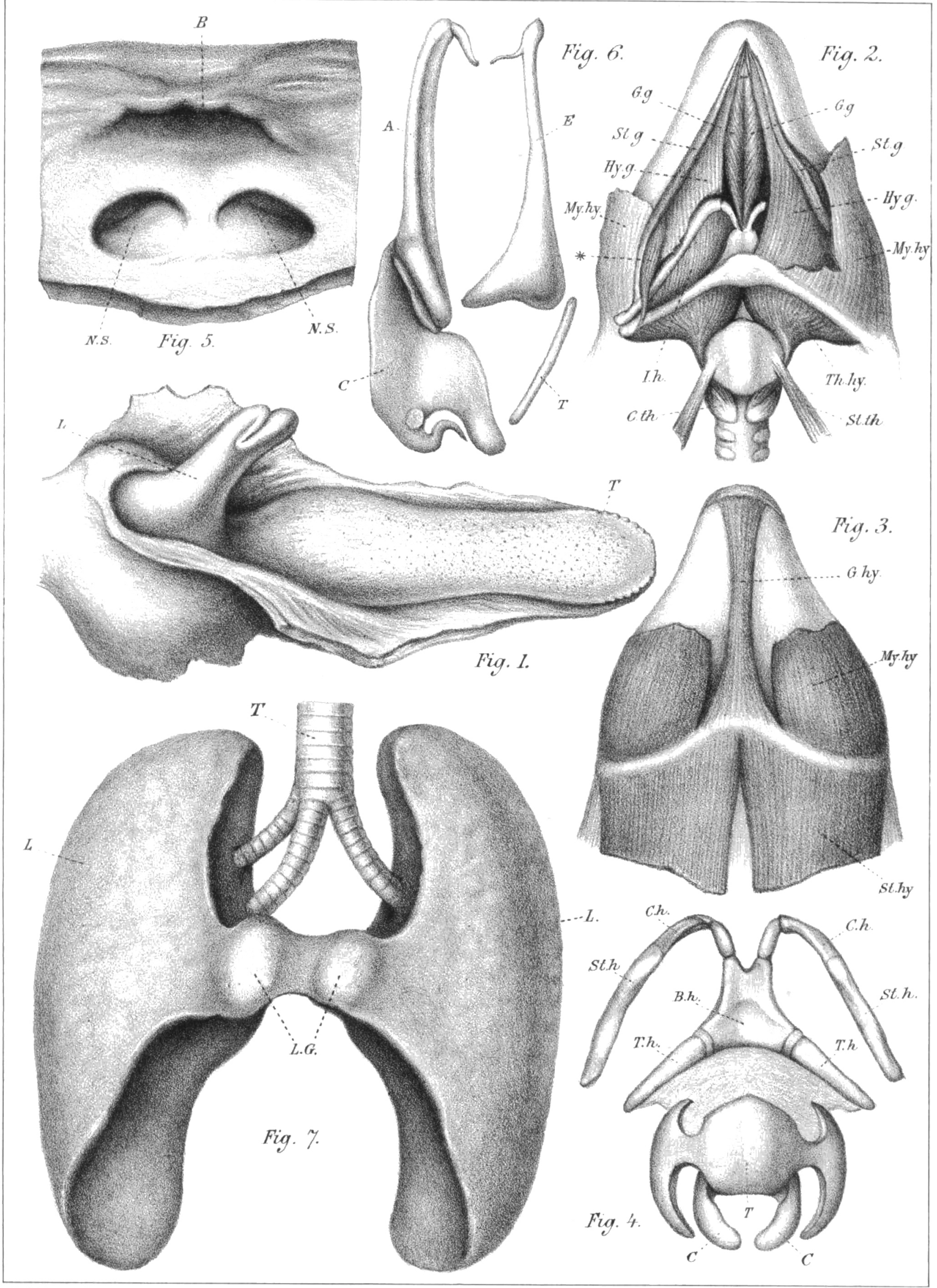

